Nediljko Budisa, Anja Hümpel

\title{
8. Themenbereich synthetische Biologie: Neue Möglichkeiten an der Grenze von Chemie und Biologie ${ }^{1}$
}

\subsection{Terminologie}

Die Bedeutung des Begriffs „synthetische Biologie“ ist unter jenen, die auf diesem Gebiet arbeiten oder dessen Entwicklung beobachten, sehr umstritten. Während einige Forschende der Meinung sind, dass es sich bei der synthetischen Biologie um eine neue Disziplin handle, verstehen andere darunter lediglich eine Erweiterung von etablierten Bereichen klassischer Forschungsgebiete wie Molekularbiologie, Biochemie, Bioinformatik und Biotechnologie. Selbst wenn es schwierig ist, zum jetzigen Zeitpunkt eine endgültige Definition zu formulieren, wird die synthetische Biologie mittlerweile im Allgemeinen als ein Forschungsgebiet mit großem Potenzial für die akademische und anwendungsbezogene Forschung betrachtet.

Wie ließe sich „synthetische Biologie“ am einfachsten definieren? Wessen Arbeiten würde man diesem Fachgebiet zuordnen? Die beste Erklärung liefert vielleicht Cricks Zitat aus dem Jahre 1965, mit dem er sich als Molekularbiologe bekennt:

„I myself was forced to call myself a molecular biologist because when inquiring clergymen asked me what I did, I got tired of explaining that I was a mixture of crystallographer, biophysicist, biochemist, and geneticist, an explanation which in any case they found too hard to grasp." (Crick, 1965)

Die heutige Situation der synthetischen Biologie ist ähnlich - was nicht überrascht, angesichts der Bandbreite der Fragen, die synthetisch-biologische Forschung zu einem fachübergreifenden Unterfangen machen, das Beiträge aus mehreren Disziplinen vereint, darunter insbesondere Molekular-, Zell- und Mikrobiologie, Systembiologie, Synthetische Chemie, Biophysik, Materialwissenschaften, Systemtechnik, Systemtheo-

1 Der vorliegende Text von Nediljko Budisa wurde erstmalig im Themenband ,Synthetische Biologie" vorgestellt (2012:85-115). Die Kernaussagen und Handlungsempfehlungen sind aktualisiert. 
rie und Computerwissenschaften. Die Synthetische Biologie umfasst verschiedene Kompetenzen und Ansätze, so zum Beispiel die Erzeugung von gentechnisch veränderten Organismen, künstlichen Protozellen und synthetischen Genomen, das Erarbeiten von Modellen regulatorischer Signal- und Stoffwechselwege und schließlich deren Umsetzung in technische Konzepte bis hin zur Herstellung von Kompatibilität mit Prozessen der Verfahrenstechnik.

Nach der Entdeckung von Restriktionsenzymen in den 1970er Jahren waren Begriffe wie "genetic engineering“ und „bioengineering“ in der internationalen biologischen Forschung zunächst populärer als „synthetic biology“. In den 1990er Jahren dagegen war insbesondere in den USA vor allem von „synthetic genes“ die Rede. In den 1970er Jahren wurde mit dem Begriff „synthetic biology“ gelegentlich auch die klassische Gentechnologie bezeichnet, die zur Herstellung von rekombinanten Proteinen oder der Erzeugung transgener Organismen eingesetzt wurde. Seit Anfang des neuen Jahrtausends wird der Begriff „synthetic biology“ von einer Forschungsgemeinschaft, die der Biologie, der Informatik und den Ingenieurwissenschaften entstammt, verwendet. Das Forschungsziel besteht darin, biologische „Bauteile“ oder biologische Systeme zu konstruieren. Als wissenschaftliche Disziplin wurde die synthetische Biologie erst im Jahre 2004 auf dem ersten internationalen Kongress zu diesem Thema etabliert. ${ }^{2}$

Aus chemischer Sicht bedeutet synthetische Biologie in der Regel die Verwendung nicht natürlicher (nicht-kanonischer) Moleküle oder Molekülteile, um natürliche biologische Systeme zu beeinflussen oder umzugestalten, mit dem Ziel, ihre Funktionsweise besser zu verstehen oder - längerfristig - neue Produktionsstämme zu entwickeln. Mit anderen Worten, die Idee besteht darin, biologisches Verhalten zu erzeugen, ohne eine exakte Kopie des natürlichen Systems herzustellen. Für die weltweit meisten Arbeitsgruppen auf dem Gebiet der synthetischen Biologie bedeutet synthetische Biologie dagegen die Verwendung natürlicher Teile biologischer Systeme (BioBricks, DNA-Fragmente, Proteine usw.), mit dem Ziel, Systeme zu konstruieren, die nicht im Zuge der natürlichen Evolution entstanden sind. Aufgrund dieser unterschiedlichen Ansätze werden in der gegenwärtigen Forschung Begriffe wie „synthetisch“, „,künstlich“, „orthogonal“, „unnatürlich“, „nicht natürlich“, „,nicht kanonisch“, „Surrogat“ und dergleichen ohne Einheitlichkeit bezüglich ihrer Bedeutung verwendet.

Die Übertragung von Ideen aus der Forschung zur künstlichen Intelligenz auf die Biologie führte zu Studien zu „künstlichem Leben“ (,artificial life“). Biologische Systeme werden in Computermodellen simuliert (und auch umgekehrt fließen biologische

2 Synthetic Biology 1.0 (10.-12.06.2004) am Massachusetts Institute of Technology (USA). Siehe Auflistung einschlägiger Konferenzen online unter: http://syntheticbiology.org/Conferences.html [28.03.2014]. 
Konzepte wie das der Evolution in die Softwareentwicklung ein). Dieser Ansatz basiert auf der Annahme von Modularität als Grundprinzip für das Funktionieren lebender Systeme. Das Ziel besteht letztendlich in der Erschaffung neuer Organismen durch die rationale Verknüpfung standardisierter biologischer Teile, die aus ihrem natürlichen Zusammenhang genommen wurden. Auf diese Weise sollen lebende Systeme in eine Liste von Bestandteilen zerlegt werden, die zu einem bestimmten Zweck neu verbunden werden können. Interessanterweise lässt sich eine Zelle mithilfe von Begriffen aus der Informationstheorie und Kybernetik als eine Maschine betrachten, die Informationen verarbeitet, die von einem genetischen Programm vorgegeben werden.

\subsection{Synthese von „Leben“ in der synthetischen Biologie}

Mit der synthetischen Biologie beschäftigt sich mittlerweile eine schnell wachsende wissenschaftliche Gemeinschaft, die einen breiten Bereich von Forschungsgebieten abdeckt. Das Fachgebiet wird von wenigen Forschungsbereichen dominiert, darunter genombasiertes Engineering von Zellen, Protozellenforschung, Engineering von Stoffwechselwegen und „DNA device design“, basierend auf dem Modularitätsprinzip, einer Standardisierung und präzisen Vorhersagemodellen unter Ausnutzung von aus der Informatik entliehenen Konzepten (Budisa, 2012). Alle drei Bereiche versuchen, sich von dem jeweiligen Forschungsgebiet, dem sie entstammen, (z. B. Gentechnologie und chemische Forschung über den Ursprung des Lebens) abzugrenzen, indem sie die „Synthese von Leben“ als ein Hauptziel der Forschung angeben. Man nimmt nämlich an, dass die Vereinfachung biologischer Systeme zu modularen und abstrakten Netzwerken es möglich macht, lebende Systeme von Grund auf nachzubauen und sogar die „Synthese von Leben“ in den Bereich des Machbaren rückt. Dabei wird die Erschaffung eines „Minimalorganismus“ als höchstes Ziel all dieser Bemühungen definiert. Dahinter steckt die Idee, dass Bakterien mit etablierten Minimalgenomen mit jeder gewünschten Funktion oder jedem gewünschten Prozess ausgestattet werden können. Tatsächlich beruht die gesamte Methodik in gewisser Weise auf einem klassischen, gentechnischen Ansatz, der auf Knock-out-Mutagenese basiert. Dadurch wird die Synthese von Leben lediglich zu einem Abgrenzungskriterium der synthetischen Biologie gegenüber der rekombinanten DNA-Technologie stilisiert (Schummer, 2011).

Die Technologie der Oligonukleotidsynthese hat in der Gentechnik und der Molekularbiologie eine Vielzahl von neuen experimentellen Ansätzen ermöglicht. Die Oligonukleotidsynthese beispielsweise hat seit den 1960er Jahren eine wesentliche Rolle in der biologischen Forschung gespielt (Nirenberg, 2004). Ein Jahrzehnt später meldete die Presse „Leben im Reagenzglas“", nachdem Sol Spiegelman Viruspartikel mit syntheti- 
scher RNA erzeugt hatte (Spiegelman et al., 1970). Im Verlauf der folgenden Jahrzehnte wurde die oligonukleotidbasierte Technologie weiterentwickelt, bis Eckard Wimmer im Jahre 2002 schließlich die Synthese des vollständigen Genoms des Poliovirus gelang (Cello et al., 2002). Hierbei ist allerdings zu bedenken, dass die erfolgreiche Synthese immer längerer Oligonukleotide zwar ein technischer, aber kein konzeptioneller Fortschritt ist. Im Jahre 2010 verkündete das US-amerikanische J. Craig Venter Institute die Herstellung der „ersten sich selbst replizierenden synthetischen Bakterienzell“ “ auf ihrer Webseite, ${ }^{3}$ ein Erfolg, der ebenfalls auf komplexer oligonukleotidbasierter, klassischer Gentechnologie beruht. Um jedoch wirklich „synthetisches Leben“ zu erschaffen, muss man notwendigerweise eine Vorstellung davon haben, wie man die Konstruktion eines Organismus von Grund auf angeht, wie man die vier Nukleobasen Adenin (A), Cytosin (C), Guanin (G) und Thymin (T) in einer bestimmten Abfolge zu Genen anordnet, sodass ein neues, aber dennoch gänzlich vorherbestimmtes Ergebnis entsteht. Derzeit ist man jedoch lediglich in der Lage, die genetischen Blaupausen von Organismen zu kopieren, wie es Venter, Wimmer, Spiegelman und viele andere bereits unzählige Male getan haben.

Daher kann man, ohne den wissenschaftlichen Wert und das herausragende technische Niveau dieser Arbeiten in Frage zu stellen, sagen, dass zum Beispiel Venters Experiment streng im Rahmen der klassischen Gentechnologie durchgeführt wurde - mit dem Ergebnis eines geringfügig genetisch modifizierten Bakteriums. Die oben angesprochene Herstellung einer ersten sich selbst replizierenden synthetischen Bakterienzelle durch das J. Craig Venter Institute beinhaltete, dass DNA aus einer Zelle mit dem Zytoplasma einer anderen kombiniert wurde. Dieses Vorgehen ähnelt ein wenig den Verfahren zur somatischen Protoplastenfusion, die bereits in den 1970er Jahren bei Pflanzen etabliert wurden (Gamborg, 1975), obwohl die Komponente des „wholegenome engineering“ bei diesen früheren Bestrebungen sicher fehlte. Zweifellos ist Venters Arbeit noch immer weit davon entfernt, die Konstruktion synthetischer Lebensformen tatsächlich zu beherrschen, aber es ist der erste Schritt auf dem Weg zur technischen Realisierung dieses interessanten Ziels. Kurz, man kann weder von der „Erschaffung“ einer Bakterienzelle sprechen, noch davon, die Konstruktion synthetischer Lebensformen zu beherrschen, wohl aber von einem signifikanten technischen Fortschritt, der die Grenzen des Machbaren auf dem Gebiet der DNA-Synthese beachtlich verschiebt.

3 www.jcvi.org/cms/research/projects/first-self-replicating-synthetic-bacterial-cell/overview [11.04.2014]. 


\subsection{Synthese von „Leben“ in der Chemie}

In den Frühstadien der modernen Chemie zu Beginn des 19. Jahrhunderts erwies sich die Synthese komplexer, aus Pflanzen oder Tieren isolierter Substanzen als schwierig oder nahezu unmöglich, und viele physiologische Phänomene waren einer experimentellen Analyse nicht zugänglich. Dies ließ Raum für die Überzeugung, dass die Bildung organischer Verbindungen von einer bestimmten „Lebenskraft“ (vis vitalis) gesteuert wird, die nur in lebenden Organismen wirkt (Hein, 1961). Lebewesen wurden in diesem Sinne von unbelebten Dingen als inhärent verschieden angesehen (Fontecave, 2010). Diesem metaphysischen Konzept widersprechen die Möglichkeiten der synthetischen Chemie. Das berühmteste Beispiel ist die Synthese von Harnstoff vor mehr als 150 Jahren. Wöhler und Liebig zeigten damit, dass natürliche organische Verbindungen grundsätzlich chemisch synthetisiert werden können (Multhauf, 1966). Das Konzept der synthetischen organischen Chemie kann folgendermaßen zusammengefasst werden: Komplexe Verbindungen werden schrittweise und in kontrollierter Weise aus einfachen Verbindungen synthetisiert. Dies führte im 19. Jahrhundert zu der Definition eines ehrgeizigen Ziels der organischen Chemie: der künstlichen Synthese sämtlicher natürlicher organischer Substanzen (Fischer, 1907).

Emil Fischer (1852-1919) ist nicht nur für seine bahnbrechenden Arbeiten zur Synthese von Kohlenhydraten, Nukleotiden und Alkaloiden bekannt, sondern auch als Visionär und einer der berühmtesten Verfechter des Fortschritts in der synthetischen Chemie. Darüber hinaus glaubte er, dass die chemische Synthese von Leben ein realistisches Ziel sei. In diesem Glauben erarbeitete er zu Beginn des 20. Jahrhunderts das Programm der "chemisch-synthetischen Biologie" (Fischer, 1915). Dieses Programm ist ein frühes Beispiel für ein Konzept der synthetischen Biologie, da er darin erstmalig erklärt, dass der Stoffwechsel lebender Zellen durch den Einsatz synthetischer Verbindungen beeinflusst und sogar verändert werden könne und solle, um neuartige Fette, Wachse und Proteine zu erzeugen. Fischer glaubte, dass Modifikation, Gestaltung und Erschaffung von Organismen mithilfe chemischer Verfahren eine Art Beginn eines großen Zukunftsprojekts seien. Er erwartete, dass neue, auf synthetische Weise erzeugte Lebensformen mit einer neuartigen oder alternativen chemischen Zusammensetzung fundamentale Vorteile gegenüber den bekannten Lebewesen haben würden und somit ein großes Potenzial besäßen, aus dem ein technologischer Nutzen für die Gesellschaft gezogen werden könnte (Fischer, 1907). Fischers Vision einer chemisch-synthetischen Biologie ist die einer spezifischen chemischen Modifikation von Organismen und ihrem Stoffwechsel für industrielle und technische Zwecke (Yeh/Lim, 2007).

Die ingenieurtechnische Sichtweise der synthetischen Biologie geht von der Implementierung von Modularität, Standardisierung und präzisen Vorhersagemodellen auf diesem Gebiet aus - ähnlich wie bei der Entwicklung von elektronischer Software. 
Nach dieser Ansicht kann ein System als modular beschrieben werden, wenn seine Bestandteile funktionell getrennt und neu kombiniert werden können. Demnach ist die moderne Biologie in hohem Maße modular, angefangen mit den chemischen Grundbausteinen - Nukleotiden und Aminosäuren - bis hin zu höheren Organisationsebenen wie Zellen, Organismen und ganzen Populationen (Agapakis/Silver, 2009). Andererseits folgt die zeitgenössische chemisch-synthetische Biologie zumindest teilweise Fischers Vision mit dem eindeutigen Ziel, Vorläufersubstanzen in lebende Zellen einzuschleusen, die in der Natur nicht vorkommen und somit als nicht-kanonische Moleküle klassifiziert werden können (Budisa, 2004; Herdewijn/Marlière, 2009). Diese Moleküle haben ihren Ursprung größtenteils in den Labors der organischen Chemie, daher sind den strukturellen Gestaltungsmöglichkeiten hierbei nahezu keine Grenzen gesetzt. Das langfristige Ziel könnte die Erzeugung von teilweise synthetischen lebenden Zellen mit vererbbaren und spezifischen chemischen Veränderungen in Genom, Proteom und Metabolom sein.

Um dieses Ziel zu erreichen, muss man jedoch klassische mimetische Ansätze, die auf diesem Gebiet noch immer dominieren, aufgeben und versuchen, radikale chemische Veränderungen in den Monomeren biologischer Makromoleküle wie Nukleinsäuren, Proteinen oder Sacchariden, oder in Stoffwechselzwischenprodukten zu nutzen (Budisa, 2005). Obwohl die letzten Jahrzehnte gekennzeichnet sind von der Forschung nach effizienten Möglichkeiten zur vollständigen oder teilweisen chemischen Synthese von Genomen, zusätzlichen Nukleinbasen und Basenpaaren, Alternativen für das Zuckerphosphatrückgrat der DNA, nicht-kanonischen Aminosäuren, die zur Proteintranslation geeignet sind, sowie dem Engineering von Transkriptions- und Translationsmaschinerie, steht das Gebiet noch ganz am Anfang einer langen Entwicklung zu einer chemisch-synthetischen Biologie. Deshalb sollte das Ziel in der Schaffung oder (zumindest) Neuprogrammierung von Lebewesen durch die Verwendung von nichtkanonischen Molekülen liegen, um so neu entstehende Eigenschaften des Systems zu etablieren - entweder nach den Grundprinzipien oder durch künstliche Evolution. Sobald die Vermehrung künstlicher genetischer Sequenzen (synthetische Gene, synthetische Proteine, synthetische Stoffwechsel und Grenzsysteme) mit ständig wachsendem Anwendungsbereich gelungen ist, wird die Erzeugung von chemisch modifizierten Organismen (CMOs) mit neuartiger Biologie (Xenobiologie) möglich werden (Schmidt, 2010). 


\subsection{Top-down-Ansätze in der synthetischen Biologie}

Der Top-down-Ansatz beruht auf der Vorstellung, dass der derzeit direkteste Weg zu synthetischen Systemen darin besteht, die Komplexität existierender biologischer Systeme zu reduzieren. Man nimmt an, dass der Einsatz der synthetischen Biologie beim Engineering komplexer Systeme und der Umgestaltung biologischer Komponenten zu minimalen Zellfabriken einen großen Fortschritt hin zu effizienten und sicheren biotechnologischen Anwendungen bedeutet. Dabei können Minimalzellen mit synthetischen Genomen (oft als „Chassis“ bezeichnet) als eine Art Plattform dienen, auf der praktisch jede gewünschte Verbindung erzeugt werden kann. Diese Plattformen werden für weitere Untersuchungen auf dem Gebiet der synthetischen Biologie verwendet, darunter (a) die Konstruktion komplexer genetischer Schaltkreise, (b) die Gestaltung maßgeschneiderter Stoffwechselwege und (c) die Erzeugung orthogonaler biologischer Systeme. Man erwartet, dass diese Bestrebungen die Konstruktion von maßgeschneiderten Zellen ermöglichen werden.

Im Zentrum der gegenwärtigen synthetischen Biologie stehen Bestrebungen, konstruierte biologische Systeme in zunehmend größerem Maßstab aufzubauen. Das Chassis oder die Zelle als Kernelement biologischer Systeme ist ein komplexes Netzwerk molekularer Wechselwirkungen mit einem erheblichen Potenzial für unerwartete Effekte, die eine korrekte Ausführung der Konstruktion stören können. Das trifft selbst für bezüglich ihrer Genomgröße relativ kleine Bakterienzellen zu, wie zum Beispiel Escherichia coli. Derzeitig gibt es folgende Strategien zur Lösung dieses Problems:

1. Reduktion der Genomgröße: Dies kann entweder durch Reduktion der Genome bereits bestehender, industriell bewährter mikrobieller Stämme wie E. coli geschehen oder durch Modifikation oder De-novo-Synthese von außergewöhnlich kleinen Genomen. Man hofft, durch einen solchen Ansatz grundsätzliche Einblicke in die minimale Funktionsweise einer Zelle zu gewinnen. Darüber hinaus besteht das Ziel letztendlich im Bau einer Zelle von minimaler Komplexität, die vollständig verstanden werden kann, obwohl Ergebnisse aus jüngster Zeit darauf hinweisen, dass diese Idee in gewisser Weise naiv sein könnte (Yus, 2009). Es ist allgemein anerkannt, dass Organismen mit kleinen Genomen entweder durch einen Top-down- oder einen Bottom-up-Mechanismus entstanden sind. Die Minimalgenome von „Urorganismen“ sind durch die Addition von Genen durch eine Art evolutionäres „Aufstocken“ entstanden (Bottom-up), die Minimalgenome „moderner“ Organismen dagegen durch die Reduktion des Genoms durch evolutionären Selektionsdruck (Top-down). Das Minimalgenom von Mykoplasmen beispielsweise entwickelte sich durch Selektionsdruck, allerdings wird diese Genomreduktion meist naiver Weise als eine Reduktion 
der Komplexität missverstanden, was nicht der Fall ist (für nähere Einzelheiten sei z. B. auf Feher et al., 2007 verwiesen).

2. Anwendung von In-vitro-Plattformen: In-vitro-Plattformen ermöglichen erheblich mehr Freiheitsgrade bei der Systemmanipulation und -analyse und reduzieren zugleich die Komplexität des Systems dadurch, dass die Zusammensetzung der Zelle zu einem bestimmten Zeitpunkt festgehalten und auf wesentliche Teile der Zelle (z. B. Membranen) verzichtet wird. Trotz der geringeren Komplexität werden zellfreie Systeme recht erfolgreich eingesetzt, um sehr komplexe Syntheseaufgaben zu bewältigen, vor allem die zellfreie Synthese von Proteinen. Der Schwerpunkt liegt dabei aber derzeit auf Anwendungen im Labormaßstab (Siegel et al., 2010).

3. "Channelling“: Neuere Ergebnisse weisen darauf hin, dass sich beispielsweise durch die Anordnung der Enzyme eines Stoffwechselwegs in einen geeignet organisierten Komplex die Reaktionsgeschwindigkeit erhöhen und die Konzentration von Zwischenprodukten verringern lässt. Der Komplex isoliert den betreffenden Signalweg räumlich vom restlichen Stoffwechsel. Obwohl dieser Ansatz für den Aufbau von Stoffwechselwegen sehr vielversprechend ist, stehen derzeit nur sehr elementare Werkzeuge zur Verfügung, um diese Strategie als eine Plattform zur Konstruktion von Systemen zu nutzen (Dueber et al., 2009).

4. Orthogonalisierung biochemischer Systeme: Prozesse, die losgelöst vom biologischen Kontext in lebenden Zellen stattfinden, werden mit dem Begriff Orthogonalität beschrieben. Die Robustheit und Leistung von künstlichen orthogonalen Vorgängen kann durch Ausnutzung natürlich vorkommender orthogonaler Systeme wesentlich verbessert werden. Zu den neuesten Entwicklungen gehört die Orthogonalisierung von Netzwerken durch systematisch evolvierende Proteine (Acevedo-Rocha/Budisa, 2011). Dabei ist es möglich, einige Interaktionen in einem Netzwerk zu entfernen oder zu schwächen und andere einzuführen oder zu verstärken, bis ein bestimmter biochemischer Prozess ohne (übermäßige) Störung durch andere Prozesse ablaufen kann. Ein archetypisches Beispiel ist die von Schultz entwickelte zweifache Selektionsstrategie zur Entwicklung orthogonaler tRNA-Aminoacyl-tRNA-SynthasePaare, bei der eine positive Selektion angewendet wird, um erwünschte neuartige Interaktionen zu selektieren, und ein negativer Screen zum Einsatz kommt, um unerwünschte Wechselwirkungen zu eliminieren (Hoesl/Budisa, 2012). Diese Strategie wurde kürzlich auch auf die Selektion von orthogonalen Ribosomen angewendet, die nur mit einem spezifischen Satz von zellulären mRNAs interagieren, sowie auf ein orthogonales Ribosom-tRNA-Paar (Wang et al., 2007). Dieser Schritt ermöglicht die isolierte Implementierung neuartiger genetischer Codes auf einer kleinen Untereinheit des genetischen Materials ein eleganter Ansatz zum Engineering des 
genetischen Codes, obwohl dabei ein zweiter Expressionskanal in der Zelle etabliert wird. Dies steht in einem gewissen Widerspruch zu dem derzeit zentralen Gedanken bei der Assemblierung von Biosystemen, nämlich der Standardisierung auf einen Kernbestand von genetischen Elementen.

Die Reduktion der Genomgröße und die Orthogonalisierung biochemischer Systeme waren im letzten Jahrzehnt die am weitesten fortgeschritten Bestrebungen in der synthetischen Biologie (Panke, 2008). Während rationalisierte Genome unter Produktionsbedingungen getestet wurden, stellte sich dies für orthogonale Stämme mit verändertem genetischem Code als schwierig heraus, da der bislang erreichte Grad der Orthogonalisierung in der Regel unzureichend ist. Obwohl mit neuartigen Aminosäuren beladene tRNAs diese wie gewünscht in rekombinante Proteine einbauten, wurden dieselben Aminosäuren außerdem zu zahlreichen anderen Positionen im Genom fehlgeleitet, an denen das entsprechende Codon eigentlich für eine andere Funktion verwendet wird. Diese (unerwünschte) Nebenwirkung führt in der Regel zu schlechtem Zellwachstum und geringer Produktivität. In einzelnen Fällen konnten diese Probleme zwar überwunden werden, aber eine robuste Strategie, die an der Ursache des Problems ansetzt, fehlt. Die Entwicklung von neuen Methoden ist hier unerlässlich. Im Einklang damit stehen Bemühungen, DNA-Bauteile und -Vektoren (wie BioBricks) zu „standardisieren“, DNA- oder RNA-Schaltkreise und -Logikgatter zu generieren und Gene, Genome, Plasmide und Signalwege zu konstruieren, umzugestalten oder chemisch zu synthetisieren. Darüber hinaus wird erwartet, dass Bestrebungen zur Konstruktion der "Minimalzelle“ und das Konzept der „Orthogonalität“ auch zu unserem Verständnis von biologischen Prinzipien und dem Sinn des Lebens beitragen (Jewett/Forster, 2010).

\subsection{Bottom-up-Ansätze in der synthetischen Biologie}

Unter dem Bottom-up-Ansatz versteht man die Erzeugung synthetischer Systeme von Grund auf durch schrittweise Steigerung der Komplexität und der funktionellen Diversität. Das Ziel ist, zukünftig ganze biologische Systeme aus anorganischer Materie herstellen zu können. Um Protozellensysteme (s. u.) aus elementaren Bausteinen (z. B. Aminosäuren, Lipiden, Nukleotiden oder synthetischen Monomeren) zu synthetisieren, können gesteuerte molekulare Assemblierungsprozesse eingesetzt werden. Die Grundbausteine können im Prinzip biologischen, organischen oder sogar anorganischen Ursprungs sein. Ziel des Bottom-up-Ansatzes ist es, einen vollständig künstlichen Organismus zu erschaffen, wenn irgendwann nicht nur das Genom, sondern auch 
alle anderen Komponenten in vitro synthetisiert werden können. Die Protozellenforschung kann als ein Beispiel hierfür dienen.

Darüber hinaus kann der Bottom-up-Ansatz auch eine solide Basis für die Untersuchung von Proteinen oder enzymatischen Reaktionen in einem umgrenzten Raum (innerhalb eines Vesikels von kontrollierter Größe) oder für die kontinuierliche Produktion und Freisetzung von bioaktiven Verbindungen an einer Oberfläche darstellen. Ein anderes interessantes Beispiel ist die Rekonstruktion von künstlichen Organellen als ein Modell zum Engineering von biologischen Kompartimenten und der Konstruktion von mimetischen Systemen. Man nimmt an, dass die allmähliche Steigerung der Komplexität beim Bau dieser Systeme zu einem besseren Verständnis entsprechender natürlicher Systeme beiträgt. Beispielsweise wurde die Durchführbarkeit der Proteinoder DNA-Produktion in von künstlichen Membranen begrenzten Kompartimenten bereits gezeigt (Luisi, 2007). Die unmittelbare Herausforderung besteht darin, diese verschiedenen Ansätze zu integrieren, um den molekularen Systemen eine neue Ebene der Komplexität hinzuzufügen, welche die Erhaltung der genetischen Information mit Synthesekapazitäten vereint.

Protozellen sind zellähnliche Strukturen, die räumlich durch eine wachsende Membran begrenzt sind und replizierbares biologisches Material enthalten. Idealerweise bilden sie selbstorganisierende chemische Systeme (z. B. Oparinsche Koazervate), ${ }^{4}$ die zur Selbstreproduktion und Selbstreplikation in der Lage sind. Die aktuelle Forschung auf diesem Gebiet setzt größtenteils die Tradition früherer Arbeiten über den Ursprung des Lebens fort.

Das Hauptziel besteht darin, den Übergang von komplexer, abiotischer Chemie zu einfacher Biologie zu verstehen und experimentell zu bewältigen, das heißt, die Entstehung komplexer chemischer Gefüge zu ermöglichen, die alle Kriterien für Leben erfüllen (siehe Abschnitt 8.7.2). Eine andere Motivation für die Protozellenforschung ist die Forschung zu künstlichem Leben (,artificial life“, abgekürzt als AL), zu dem traditionell das In-silico-Design von Systemkonstruktionen gehört, die lebensähnliches Verhalten zeigen (,soft AL“), sowie die Robotik („hard AL“). In diesem Zusammenhang bezeichnet man mit „wet AL“ die Erschaffung lebensähnlicher Protozellen auf Basis von Kohlenstoffverbindungen in Wasser, mit reproduzierbaren Sätzen autokatalytischer chemischer Zyklen, die in geeigneter Weise koordiniert sind. Zu diesen autokatalytischen Zyklen gehört die Replikation von Informationsträgern, die innerhalb der Membrangrenzen abläuft und mit inneren Stoffwechselreaktionen so gekoppelt ist, dass sie die Selbsterhaltung des Systems ermöglicht (Rasmussen et al., 2008). Im Idealfall sollten 
auch die Bedingungen für die Koordination von Wachstum und Formänderung der Zellmembran (d. h. Zellwachstum und -teilung) festgelegt sein. Auf der Ebene einfacher physikochemischer Gesetze laufen die Prozesse des Vesikelwachstums und der Reproduktion als eine Folge der Unterbrechung der Raumsymmetrie einer synthetischen Protozelle ab (Szathmary et al., 2005). Schließlich kann die Protozellenforschung in der Medizin zur Konstruktion von Systemen zur Arzneimittelverabreichung eingesetzt werden, beispielsweise zum Verkapseln von Arzneimittelcocktails in Liposomen und verschiedenen Nanopartikeln (Luisi/Stano, 2011).

\subsection{Systems Engineering und synthetische Biologie}

Die vorherrschende Meinung unter Forschenden auf dem Gebiet der synthetischen Biologie ist, dass die Biologie sich ohne Engineering nicht erheblich weiterentwickeln kann, und die Ingenieurtechnik in diesem Jahrhundert durch die Biologie beherrscht werden wird. Die synthetische Biologie macht sich eine Strategie zu eigen, die häufig von Ingenieuren angewendet wird, um Einblicke in die Funktionsweise einer Reaktion, Maschine oder eines Prozesses zu gewinnen. Dieser Ansatz:

„[...] is driven by the notion that only when principles borrowed from mathematics, fluid mechanics, materials science, etc. are applied to classical problems in developmental biology, will sufficient comprehension be achieved to permit successful understanding and therapeutic manipulation of embryos. As it now stands, biologists seldom possess either skills or interest in those areas of endeavour. Thus, we have determined that it is easier to educate engineers in the principles of developmental biology than to help biologists deal with the complexities of engineering." (Gordon/Melvin, 2003)

Die Perspektive des systemweiten Engineerings ist demnach ein typischer Aspekt der synthetischen Biologie. Zum Beispiel bezeichnet „reverse engineering“ den Prozess der Analyse eines Systems mit dem Ziel, die Bestandteile des Systems und ihre Wechselbeziehungen zu identifizieren und Repräsentationen des Systems in einer anderen Form oder auf einer höheren Abstraktionsebene zu erzeugen. Die meisten traditionellen Fachgebiete der Biologie sind auf die Analyse und Aufgliederung biologischer Systeme ausgerichtet und können somit als „reverse engineering“ betrachtet werden. Im Gegensatz dazu betreibt die synthetische Biologie „forward engineering“ mit dem Ziel, biologische Systeme zu konstruieren und synthetisieren, die so in der Natur nicht vorkommen. Die synthetische Biologie wirft dabei einige zentrale Fragen auf. Die erste 
Frage ist, wie sich biologische Grundfunktionen und -prozesse in künstliche zelluläre Einheiten integrieren lassen. Die nächste Frage ist, wie sich umgrenzte Systeme erzeugen lassen, die zur Selbsterhaltung und sogar zur Evolution in der Lage sind. Eine weitere Herausforderung ist die Erschaffung eines vollständig synthetischen biologischen Systems. Schließlich stellt sich die Frage, welche Voraussetzungen die synthetische Biologie erfüllen muss, um durch Konstruktion, Umgestaltung und Engineering funktioneller Einheiten und Systeme, die skalierbar und für synthetische Zwecke geeignet sind, einen wesentlichen Beitrag zur Biotechnologie zu leisten. Die auf bakteriellen Biokatalysatoren basierende industrielle Biotechnologie ist beispielsweise generell von der unter den Betriebsbedingungen mangelnden Stabilität der natürlichen oder gentechnisch veränderten Mikroorganismen betroffen. Ursache hierfür ist oft eine nicht beabsichtigte und dennoch unvermeidliche Verbindung zwischen dem nativen biologischen Programm des Wirts und der Expression der gewünschten enzymatischen Aktivitäten. Die Ansätze der synthetischen Biologie zur Lösung dieses Problems beinhalten die Konstruktion künstlicher Zellfabriken, zum Beispiel durch Orthogonalisierung der Proteinsynthese, und die Verknüpfung mit dem Engineering von Stoffwechselwegen, um eine ökonomische Produktion von Proteinen aus Salz, Wasser, Spurenelementen und einfachen Kohlenstoffquellen zu ermöglichen.

Die Analyse der Wechselwirkungen einer großen Anzahl von natürlichen und künstlichen biologischen Modulen erfordert eine quantitative Modellierung und systemtheoretische Konzepte. Aus ingenieurtechnischer Sicht übersteigen biologische Systeme jedoch bei weitem die Komplexität künstlicher technischer Systeme. In der Elektrotechnik und der chemischen Verfahrenstechnik ist die Konstruktion neuer Systeme heutzutage ohne eine entsprechende modellbasierte Systemanalyse undenkbar. Die Erfahrung zeigt, dass systemweite Wechselwirkungen in komplexen Netzwerken auf Grundlage eines rein qualitativen Verständnisses kaum steuerbar sind. Eine quantitative Beschreibung der relevanten Untersysteme ist für eine erfolgreiche Konstruktion neuartiger biologischer Systeme dringend erforderlich. Wie genau ein Modell ein Untersystem für ein bestimmtes Konstruktionsvorhaben beschreiben muss, wird ein Thema zukünftiger systemtheoretischer Forschung sein.

Die Systembiologie hat in den letzten zehn Jahren bereits eine Grundlage an quantitativem biologischen Wissen und mathematischen Werkzeugen etabliert. Zu den neuen Herausforderungen der synthetischen Biologie zählt die Erweiterung dieser Werkzeuge vor allem in zwei Richtungen. Die erste Richtung betrifft die Konstruktion funktioneller Systeme, dazu gehören Multi-Scale-Aspekte, Verfahren zur Behandlung von Modularität, die Standardisierung von Schnittstellen sowie die Abstimmbarkeit und Komponierbarkeit von Modulen, Die zweite Richtung betrifft die Konstruktion robus- 
ter Systeme, die Behandlung stochastischer Systemeigenschaften und die Frage der erforderlichen Genauigkeit von Modellen. In den meisten neueren Studien auf dem Gebiet der synthetischen Biologie geschieht die Modellierung anlässlich von experimentellen Ergebnissen und führt so zu zahlreichen unzusammenhängenden Ansätzen. Stattdessen sollte in Zukunft die experimentelle Arbeit durch theoretische Ansätze vorangetrieben werden. Auf diese Weise ließe sich eine solide Grundlage für die integrierte Konstruktion synthetischer biologischer Systeme schaffen. Die synthetische Chemie lehrt, dass das ganze Leben gleichsam „in der Sprache der Chemie geschrieben ist“. Selbstverständlich erfordert eine vollständige Theorie lebender Systeme nicht nur die Kenntnis sämtlicher biologischer Details, sondern muss außerdem den Gesetzen der Chemie und Thermodynamik sowie einem komplexen mathematischen Formalsystem gehorchen (Binder/Danchin, 2011).

\subsection{Das Konzept des Bakteriengenoms}

\subsubsection{Definition des minimalen Bakteriengenoms}

Biologische Systeme sind in der Lage, unter verschiedenen Umweltbedingungen stabile Phänotypen zu erhalten, was mit dem Begriff „Robustheit“ bezeichnet wird. Sie können auch den Verlust funktioneller Komponenten durch Inaktivierung von Genen kompensieren. Beispielsweise war es durch Kombination mehrfacher Deletionen in den Chromosomen von E. coli und Bacillus subtilis möglich, Stämme mit unerwarteten vorteilhaften Eigenschaften zu identifizieren. Noch wichtiger war es, dass diese Arbeiten zu neuartigen Methoden zum Engineering von Chromosomen führten, die mehrfache Deletionen mit ausgeklügelten Systemen zum Monitoring der Phänotypen kombinierten (Fabret et al., 2002).

Die grundlegende praktische Motivation hinter diesen Bemühungen ist die Konstruktion von Stämmen mit modifizierten Regulationsnetzwerken und optimierten Stoffwechseleigenschaften. Die Deletion von großen, entbehrlichen Chromosomenbereichen soll einfachere Stämme mit reduziertem Energiebedarf zur Selbsterhaltung ergeben. Dies kann durch Entfernung von potenziell energieaufwendigen Prozessen wie Flagellenbildung, Sporulation, Biofilmbildung und dergleichen erreicht werden.

$\mathrm{Zu}$ diesem Ziel wurden 101 proteinkodierende Gene von Mycoplasma genitalium inaktiviert, wobei das Bakterium seine Lebensfähigkeit behielt (Gibson et al., 2010). Diese Gene sind demnach entbehrlich, das heißt für das Wachstum nicht essenziell. Es ist zu erwarten, dass weitere Experimente in diese Richtung zu einem fundamentalen Durchbruch im Verständnis der Systembiologie dieser Organismen führen. Beispielsweise 
könnten diese Experimente zu einem besseren Verständnis der Beziehungen zwischen dem Translationsapparat, der globalen Organisation metabolischer Netzwerke und der Regulation von Zellwachstumsprozessen führen. Darüber hinaus wären die Ergebnisse von industriellem Nutzen - bislang werden Bakterienstämme mit reduzierten Genomen in der Regel systematisch geprüft, um genetisch stabile Phänotypen zu finden, die ein optimales Gleichgewicht zwischen Wachstumsrate, Proteinbiosynthese, Nährstoffquellen, niedrigem Energiebedarf und Abfall aufweisen.

Obwohl Bakteriengenome sich in ihrer Größe und ihrem Genrepertoire stark unterscheiden, müssen selbst kleine Genome alle Informationen enthalten, die es der Zelle erlauben, die grundsätzlichen Funktionen zu erfüllen, die zur Aufrechterhaltung des Stoffwechselgleichgewichts notwendig sind (Mushegian, 1999). Eine Minimalzelle kann einfache Metaboliten aus ihrer Umgebung importieren, nicht aber funktionelle Proteine, daher sind Minimalzellen zur Ausführung essenzieller Funktionen auf ihre eigenen Genprodukte angewiesen. Es ist schwierig, die Untergrenzen für die Größe des minimalen Bakteriengenoms und -proteoms zu schätzen. Beispielsweise besitzt M. genitalium mit einem Genom von 540 kb 480 Protein codierende Gene, während der Endosymbiont von Blattläusen, Buchnera aphidicola (450-kb-Genom), über nur 400 Protein codierende Gene verfügt (Lagesen et al., 2010). Nach Mushegian und Koonin sollen schätzungsweise 250 konservierte Gene für eine „moderne“ Zelle notwendig und ausreichend sein (Mushegian/Koonin, 1996). Diese Zahl basiert auf der Annahme, dass Gene, die gemeinsam in unterschiedlichen Genomen vorkommen, wahrscheinlich essenziell sind. Eine weitere Reduktion des Minimalgenoms wird auch als Strategie in Betracht gezogen, um das genetische Material des letzen gemeinsamen Vorfahrens von Prokaryonten und Eukaryonten zu rekonstruieren (Koonin et al., 1997).

In diesem Sinne sind prokaryontische Genome von Endosymbionten Beispiele für natürlich evolvierte Minimalzellen, ihre Analyse kann daher Licht auf die minimalen Voraussetzungen zur Aufrechterhaltung von Leben werfen. Obligatorische intrazelluläre Parasiten wie Mycoplasma oder Zellen mit einem wirtsgebundenen Lebensstil leben in relativ unveränderlichen Nischen, die nur eine begrenzte Anpassungsfähigkeit erfordern. Es wirkt somit nur ein geringer Selektionsdruck auf die Erhaltung von Genen, die in einer geschützten Umgebung nicht erforderlich sind. Aus diesem Grund ist es kaum möglich, die Idee einer Minimalzelle exakt zu definieren - abhängig von Umweltbedingungen oder experimentellen Zielen lassen sich jeweils verschiedene essenzielle Funktionen bestimmen. Es könnte demnach eine Vielzahl von Minimalzellen geben (Mushegian, 1999).

Das bedeutet, dass das Phänomen der metabolischen Komplementierung in endosymbiontischen Bakterien diese nicht zu den optimalen Kandidaten für die Suche nach 
der Minimalform von Leben macht. Der Schwerpunkt sollte daher auf der Entdeckung von natürlich evolvierten Zellen mit eingeschränkten (reduzierten) Genomen liegen. Dabei sollte durch vergleichende Analyse definiert werden, welche Zellkomponenten notwendig und ausreichend für die Aufrechterhaltung von Leben sind, und wie dieselben Grundfunktionen des Lebens von einer Vielzahl von (oft nicht verwandten) Genen ausgeführt werden (Mushegian, 1999).

\subsubsection{Grundanforderungen an die Minimalzelle}

Die Konstruktion von Minimalzellen durch Top-down-Ansätze ist in chemischer Hinsicht ein aufwendiges und schwieriges Unterfangen. Selbst die kleinsten heute noch lebenden Zellen besitzen ein sehr komplexes Transkriptions-Translations-System und äußerst komplizierte Stoffwechselsysteme und Erbanlagen. Dagegen ist die natürliche Reduktion von Genomen in erster Linie mit dem Übergang von einer freilebenden zu einer wirtsabhängigen Lebensweise verbunden. Man sollte allerdings bedenken, dass das Konzept eines Minimalgenoms bestimmte Umweltbedingungen voraussetzt, im Idealfall (d. h. in einer nährstoffreichen Umgebung) stehen alle essenziellen Nährstoffe zur Verfügung ohne Stressbedingungen zu verursachen.

Im Folgenden wird versucht, Prozesse und Strukturen zusammenzufassen, die in der aktuellen Literatur als unbedingt essenziell für das Funktionieren von Minimalzellen definiert werden (Walde, 2010):

1. Informationsspeicherung und -verarbeitung: Speicherung und Verarbeitung von DNA (Stoffwechsel und Synthese, Replikation, Reparatur, Restriktion und Modifikation) und RNA (Stoffwechsel und Synthese, Transkription, Translation, Degradation). Die größte Kategorie konservierter Gene (ca. 80 Gene) ist an der Proteinsynthese beteiligt (Gil et al, 2004).

2. Proteinassemblierung, -prozessierung, -faltung und -sekretion: Biologische Funktionen sind vor allem das Ergebnis der Wechselwirkung von Proteinen, die sich zu Proteinkomplexen und Netzwerken organisieren. Hochdynamische Proteinkomplexe sind die Basisebene der Organisation des zellulären Proteoms. Größere Zusammenschlüsse - oft als molekulare Maschinen bezeichnet - spielen bei allen wichtigen zellulären Prozessen eine entscheidende Rolle. Proteinkomplexe interagieren miteinander und erzeugen verschiedene Netzwerkebenen - ein Merkmal, das entscheidend für die Aufrechterhaltung der zellulären Homöostase und Funktionen ist. Erste strukturelle Genomexperimente unter Einbeziehung von bekannten Komplexen in M. pneumoniae als Modellorganismus führten zu dem Schätzwert von unge- 
fähr 300 Kopien pro molekularer Maschine (140 für das Ribosom, 100 für GroELs, 100 für Pyruvatdehydrogenase; s. Kühner et al., 2009).

3. Zelluläre Strukturen und Prozesse: Zellwand, Form der Zellorganellen und Transport von Substraten müssen ebenfalls in Betracht gezogen werden. Minimalzellen können viele essenzielle Metaboliten nicht selbst synthetisieren und sind auf den Import dieser Substanzen aus der Umwelt angewiesen. Deshalb müssen zur Aufnahme der notwendigen Moleküle zahlreiche Transportsysteme vorhanden sein.

4. Energie- und Intermediärstoffwechsel: Man setzt voraus, dass Minimalzellen in einem nährstoffreichen Medium leben und wichtige Metaboliten uneingeschränkt zur Verfügung stehen. Dazu gehören Aminosäuren, stickstoffhaltige Basen (Adenin, Guanin, Uracil), Fettsäuren, Glukose, Vorstufen von Coenzymen (Nikotinamid, Riboflavin, Folat, Pantothenat und Pyridoxal) und Glukose als das Hauptsubstrat von Glykolyse, Glukoneogenese, Pyruvatstoffwechsel, Zitratzyklus und Pentosephosphatweg. Schließlich sind Elektronenübertragungsmechanismen und der Aufbau eines elektrochemischen Protonengradienten erforderlich. In bisherigen Minimalgenomen ist der Intermediärstoffwechsel normalerweise auf die ATP-Synthese reduziert, während Fettsäure-, Nukleotid- und Aminosäuresynthese fehlen (obwohl die Existenz einiger „salvage pathways“ nicht ausgeschlossen werden konnte, Yus et al., 2009).

Grundsätzlich ist die Idee eines Minimalgenoms auf der derzeitigen Entwicklungsstufe noch ein konzeptionelles Werkzeug für theoretische Betrachtungen über die minimalen Voraussetzungen für heutiges zelluläres Leben und über mögliche experimentelle Wege zur Konstruktion noch einfacherer zellulärer Systeme auf Basis eines enzymvermittelten Stoffwechsels und nukleinsäurebasierter Erbanlagen.

\subsection{Xenobiologie}

\subsubsection{Gerichtete Evolution alternativer chemischer Zusammensetzungen}

Lebende Systeme können näherungsweise als chemische Maschinen betrachtet werden, die von einem genetischen Programm gesteuert werden. Das Grundmerkmal von Leben sind standardisierte und koordinierte chemische Reaktionen in Form von gekoppelten Kreisprozessen (Stoffwechsel und Informationstransduktion), wobei Enzyme und Enzymkomplexe eine wichtige Rolle bei der Aufrechterhaltung der Homöostase spielen. Alle für die anfängliche Entwicklung und Erhaltung der Zelle notwendigen Informationen sind in Form von Nukleinsäuren gespeichert, die nach den Regeln des genetischen Codes zu Proteinen translatiert werden 
In der synthetischen Biologie ist man davon überzeugt, dass in Zellpopulationen mit vollständig integrierten neuartigen chemischen Prozessen unerwartete Lebensformen und Eigenschaften entstehen würden. Deshalb soll die Synthese chemisch modifizierter Biomoleküle (wie Aminosäuren, Nukleinbasen oder enzymatischen Kofaktoren), die in der klassischen biomimetischen Chemie eingesetzt werden (die jene Moleküle gewöhnlich außerhalb der Zelle untersucht), nur der erste Schritt auf dem Weg zur Änderung der zellulären Zusammensetzung sein. Der Grundgedanke ist, dass die synthetische Biologie unter Verwendung von biologischen Materialien die synthetische Chemie in der gleichen Weise nachahmen sollte, wie die Chemie natürliche Strukturen und Prozesse nachahmt. Im fortgeschrittenen Stadium sollen die funktionellen Eigenschaften lebender Systeme durch den Erwerb neuartiger chemischer Prozesse im Zuge der künstlichen Evolution von bestehenden Zellen weiter diversifiziert werden. In diesem Zusammenhang besteht eine wichtige Aufgabe der chemisch-synthetischen Biologie darin, die künstliche Evolution von Zellen mit veränderter chemischer Zusammensetzung zu etablieren, die lebensfähig und so robust sind, dass sie für eine unbegrenzte Dauer wachsen und sich replizieren, und zwar in genetischer Isolation von natürlichen Arten (Marlière, 2009).

Dies ist jedoch keine einfache Aufgabe, da die chemischen Prozesse in lebenden Zellen bekanntermaßen standardisiert sind. Alle derzeit bekannten Zellen verfügen über dieselbe Organisation von Hauptstoffwechselwegen und Informationsverarbeitung und denselben Satz von Makromolekülen (Nukleinsäuren, Proteine, Fettsäuren). Proteine enthalten zum Beispiel ein Standardrepertoire aus 20 kanonischen Aminosäuren, während DNA, das genetische Material, aus vier verschiedenen kanonischen Nukleotiden besteht: Adenin (A), Thymin (T), Guanin (G) und Cytosin (C). Der universelle Charakter des genetischen Codes ermöglicht zudem einen horizontalen Gentransfer über die Grenzen der biologischen Taxa hinweg. Aufgrund des hohen Grades der Standardisierung und Interkonnektivität sind alle Veränderungen der zentralen chemischen Prozesse eines lebenden Systems tendenziell letal.

Wenn ein Organismus einer Umwelt ausgesetzt wird, die so neuartig ist, dass kein bestehendes System daran angepasst ist, kann er nur durch umfangreiche Modifikation von Enzymen und Proteinen adaptieren, die ursprünglich in Reaktion auf ganz andere Umstände evolviert sind. Dies erfordert in jedem Fall eine Umschreibung des genomischen Textes durch Anhäufung und Kombination verschiedenartiger Mutationen. $\mathrm{Zu}$ diesem Zweck eignen sich Langzeitkultivierungsexperimente mit Bakterienzellen. Dem Wegbereiter dieser Arbeiten, Richard Lenski, gelang es, in einem seit 1988 andauernden Experiment mehr als 50.000 aufeinanderfolgende Generationen von E. coli zu kultivieren (Stanek et al,, 2009), 
Vor Kurzem verwendeten Marlière und Mutzel einen experimentellen Aufbau, der als „Genmotor“ oder „Genemat" bekannt ist, eine Art „automatisierter Lenski-Apparat" (Marlière et al., 2011). Diese Fluidikvorrichtung ist mit zwei Kammern ausgestattet, die abwechselnd sterilisiert werden, sodass keine kultivierte Variante der Verdünnung und der Selektion für ein gewünschtes Merkmal entgehen kann. Das Arbeitsvolumen der Kultur beträgt $25 \mathrm{ml}$, die durchschnittliche Zelldichte 109/ml; daraus ergibt sich eine Anzahl von $2 \times 1010$ Zellen im Kulturvolumen. Da die durchschnittliche Mutationsrate in E. coli 5,4 $\times$ 10-10 pro Basenpaar beträgt, gibt dieser experimentelle Aufbau unter dem gewählten Selektionsdruck ausreichend Zeit für kumulative Mutationen. Die Wachstumszyklen werden durch einen einfachen Algorithmus automatisch gesteuert: Wenn die optische Dichte der Kultur unterhalb eines Schwellenwerts liegt, wird „Erholungsmedium“ zugeführt, liegt sie darüber, wird Selektionsmedium zugesetzt. Im Gleichgewichtszustand (in Gegenwart einer Fremdsubstanz) sind Wachstums- und Verdünnungsrate gleich groß. Taucht jedoch eine Variante mit einer höheren Wachstumsrate auf, wird mehr Biomasse produziert, dies führt zu einer Zunahme der Verdünnungsrate. Demnach korreliert die Änderung der Verdünnungsrate direkt mit der Fitness der zu selektierenden genetischen Variante.

Basierend auf den oben beschriebenen Prinzipien führten Marlière und Mutzel den ersten erfolgreichen Versuch zur künstlichen Evolution von Mikroben mit einer stark veränderten chemischen Zusammensetzung der genomischen DNA durch. Dabei evolvierten E. coli-Varianten mit der Fähigkeit, auf 5-Chlorouracil (5-ClU; kurz $\chi$ ) zu wachsen, dank einer umfangreichen Modifikation des normalerweise zur Verstoffwechselung von Thymin verwendeten Biosynthesewegs. Ein E. coli-Stamm wurde durch Einführung eines Stoffwechselwegs, der in der Lage ist, $\chi$ als Ersatz für Thymin zu verwenden, für die Evolution konfiguriert. Die Zellen waren dadurch in der Lage, Chlordesoxyuridin-Triphosphat ( $\mathrm{d} \chi \mathrm{cTP}$ ) zu synthetisieren, das anschließend enzymatisch polymerisiert in genomische DNA eingebaut wurde. Obwohl die evolvierten Bakterien die Fähigkeit zum Wachstum auf Thymin behielten, ist dieses Experiment ein wichtiger Schritt auf dem Weg zur vollständigen genetischen Isolation, das heißt einer vollkommenen Abhängigkeit der Zellen von $\chi$ wobei die Zellen gleichzeitig auf kanonisches Thymin nicht mehr angewiesen sind). Schließlich sollte die gerichtete Evolution von Bakterienstämmen nicht nur synthetische DNA-Basen umfassen, sondern auch nichtkanonische Basenpaare, um die Codierungskapazität des zellulären genetischen Materials zu erhöhen. Das Ziel ist letztendlich ein integrativer evolutionärer Ansatz, der die gerichtete Evolution künstlicher Zellen mit erweiterter Codierungskapazität, neuartige genetische Codes sowie de novo erzeugte Stoffwechsel- und Informationswege beinhaltet und lebende Systeme nicht nur mit neuen chemischen Prozessen, sondern 
auch mit neuen Eigenschaften ausstattet, die im Zuge der natürlichen Evolution nicht entstanden sind (Acevedo-Rocha/Budisa, 2011).

\subsubsection{Das Konzept der genetischen Firewall}

Ein wichtiges Ziel der synthetischen Biologie besteht darin, orthogonale biologische Systeme zu konstruieren, deren genetische Ausstattung soweit verändert ist, dass daraus die genetische Inkompatibilität mit sämtlichen natürlichen biologischen Systemen auf der Erde resultiert. Eine derartige genetische Isolation synthetischer Zellen kann durch Anwendung von in der Natur nicht vorkommenden DNA-Komponenten (,Xeno-DNA“) oder einem vollständig veränderten genetischen Code erreicht werden.

Da der natürliche genetische Code für alle Lebensformen (beinahe) universell ist, verhindern grundlegende Veränderungen in seinem Aufbau den sonst natürlicherweise stattfindenden Transfer von genetischem Material zwischen synthetischen und natürlichen Mikroorganismen (horizontaler Gentransfer). Auf diese Weise würde eine genetische „Firewall“ gegen Organismen errichtet werden, die auf natürlicher DNA basieren. Aspekte der Biosicherheit von gentechnisch veränderten Zellen, in denen eine genomweite Reprogrammierung des genetischen Codes vorgenommen wurde, wurden erst kürzlich ausführlich diskutiert (Schmidt, 2010; Herdewijn/Marlière, 2009).

Spätestens seit der Asilomar-Konferenz im Jahr 1975 werden Sicherheitssysteme für gentechnologische Anwendungen entwickelt, die als Mechanismen in erster Linie die physische Isolation oder die Abhängigkeit von essenziellen Nährstoffverbindungen nutzen, die in der Umwelt nicht zur Verfügung stehen (Auxotrophie). Zu den Bedenken, die von Umweltaktivisten, politischen Entscheidungsträgern und der besorgten Bevölkerung in diesem Zusammenhang geäußert werden, zählt die Möglichkeit des horizontalen Gentransfers von gentechnisch veränderten Organismen auf Wildtyp-Arten. Das Konzept einer solchen „genetischen Brandmauer“ kann unter Umständen viel dazu beitragen, diese Befürchtungen durch die Entwicklung technischer Lösungen zu zerstreuen, die allerdings sorgfältig überdacht und geprüft werden müssen.

\subsubsection{Jenseits der Grenzen der vertrauten biologischen Welt}

Die dominierenden Themen der aktuellen Forschung auf dem Gebiet der synthetischen Biologie sind die Konstruktion genetischer Schaltkreise, das Engineering von Genomen und Stoffwechselwegen, die zelluläre Signaltransduktion sowie eine erweiterte Systembiologie. Die Vorherrschaft dieser Bereiche lässt sich eventuell durch das derzeitige Dogma der heutigen Molekular und Systembiologie erklären dass der In-vivo- 
Einsatz neuartiger (d. h. nicht-kanonischer) chemischer Reaktionen eher begrenzt ist, da hierbei in der Regel nur kleine, vernachlässigbare Variationen im grundlegenden Design lebender Zellen möglich sind. Folglich könne die Neuprogrammierung von Zellen mit synthetischen Elementen nicht mit der chemischen und funktionellen Diversität Schritt halten, die durch genetische Mutationen, Rekombination und horizontalen Gentransfer in der Evolution natürlicher Organismen erzeugt wird.

Diese Annahme wurde bereits in den 1950er und 1960er Jahren angezweifelt, als gezeigt wurde, dass beispielsweise der Einbau von nicht-kanonischen Aminosäuren in das Proteom eines Organismus tatsächlich möglich ist (Cowie/Cohen, 1957). Darüber hinaus zeigte eine Reihe von Experimenten aus jüngster Zeit unzweifelhaft, dass synthetische Verbindungen, die in natürlichen Arten nicht vorkommen, trotzdem als unverzichtbare Nährstoffe von lebenden Zellen verwendet werden können (Pezo et al., 2004). Wie zu erwarten ist, wachsen Mikrobenstämme (Auxotrophe), die vollständig mit fremden Komponenten substituiert sind, schlecht und kehren leicht zur Verwendung der kanonischen Substanzen zurück. Diesbezüglich besteht die wichtige Aufgabe der chemischsynthetischen Biologie darin, Bedingungen zur Kultivierung solcher Zellen für unbegrenzte Dauer und in genetischer Isolation von natürlichen Arten zu finden. Zweifellos würden in einem Experiment, bei dem natürliche Komponenten lebender Zellen durch fremde ersetzt werden, nicht vorhersehbare Lebensformen aus diesen Populationen erwachsen. Somit eröffnet sich die Möglichkeit einer vollkommen neuen biologischen Welt. Dabei war die Konstruktion genetisch modifizierter Organismen (im Rahmen der klassischen Genetik) nur der Beginn einer langen Entwicklung auf der Suche nach zuverlässigen Methoden zur Konstruktion und Anwendung von künstlicher Biodiversität, die es erlauben, zugleich die alte, natürliche Welt zu bewahren (Marlière, 2009).

\subsection{Problemfelder und Indikatoren im Bereich der synthetischen Biologie}

\subsubsection{Einführung und Übersicht}

Die besondere Aufgabe des Gentechnologieberichts besteht darin, das komplexe Feld der Gentechnologie in Deutschland auch quantitativ durch geeignete Indikatoren aufzuschließen. Um die komplexen Diskussionsstränge in der öffentlichen Debatte rund um die synthetische Biologie sichtbar zu machen, erfolgte dabei analog der in Kapitel 
2 beschriebenen Methodik die Erhebung eines Text-Korpus ${ }^{5}$ : Die recherchierten Texte wurden inhaltsanalytisch ausgewertet, verschlagwortet und zu Problemfeldern zusammengefasst. Abbildung 1 zeigt die so eruierten Problemfelder sowie deren quantitative Gewichtung in den untersuchten Texten innerhalb der gesetzten vier Leitdimensionen des Gentechnologieberichts. Die Abbildung illustriert dabei die Komplexität und Vernetzung der verschiedenen Diskussionsstränge, auch wenn die Darstellung immer eine Momentaufnahme bleiben muss, da die Abgrenzung der synthetischen Biologie und das Selbstverständnis der beteiligten Wissenschaftlerinnen und Wissenschaftler gegenwärtig noch diskutiert wird.

Für den Themenbereich der synthetischen Biologie wurden 2012 erstmalig Problemfelder aus der öffentlichen Debatte in Deutschland generiert und Indikatoren erarbeitet (vgl. Köchy/Hümpel, 2012:257-285). Die hier aufgeführten Diskussionsstränge entsprechen weitestgehend denen, die der Themenband zutage gefördert hatte (ebd.). Jedoch wird eine Abkehr vom theoretischen Diskurs um Lebensbegriff und Künstlichkeit zugunsten einer verstärkten Auseinandersetzung mit der praktischen Nützlichkeit der synthetischen Biologie. Entsprechend nicht mehr sichtbar sind die Problemfelder Lebensbegriff, Abgrenzung von Natur und Technik/Kultur, Ethischer Umgang mit Leben; stärker gewichtet als 2012 hingegen sind die Problemfelder Realisierung wissenschaftlicher Zielsetzungen und Anwendungshorizonte. Im Zusammenhang mit der Veröffentlichung der Forschungsergebnisse zum Grippevirus H5N1 wurde zudem vermehrt ein möglicher Missbrauch der synthetischen Biologie und eine verantwortungsvolle wissenschaftliche Praxis diskutiert. Eine solche Verschiebung der öffentlichen Debatte lässt sich vor dem Hintergrund der Etablierung des neuen Problemfeldes Biosafety/Biosecurity lesen. Die Diskussionsstränge spiegeln eine fortschreitende Konsolidierung des Forschungsfeldes, das im öffentlichen Sprechenzunehmend praktische Anwendungen und damit auch praktischen Regelungsbedarf fokussiert.

5 Für die Printmedien (a) wurde für den Zeitraum vom 01.6.2011 bis 31.05.2012 eine Volltextsuche (Stichwort: „synthetische Biologie“) in den Leitmedien SÜDDEUTSCHE ZEITUNG, FRANKFURTER ALLGEMEINE ZEITUNG, DER SPIEGEL sowie DIE ZEIT durchgeführt. Für die Internetrecherche (b) wurde am 04.06.2012 via der Suchmaschine Google eine Suche nach dem Stichwort „synthetische Biologie“ zu durchgeführt; berücksichtigt wurden die ersten zehn Treffer. Mögliche Stellungnahmen (c) wurden ebenfalls online via Stichwortsuche (,synthetische Biologie“ und in Verbindung mit „Stellungnahme“, aber auch „Analyse“, „Gutachten“, „Position“, „Perspektive“ bzw. „Thesen“) am 04.06.2012 via Google recherchiert; berücksichtigt wurden diejenigen Texte unter den ersten zehn Treffern, die als Stellungnahmen im engeren Sinne identifiziert wurden. 
Abbildung 1: Erhobene Problemfelder zur synthetischen Biologie in Deutschland

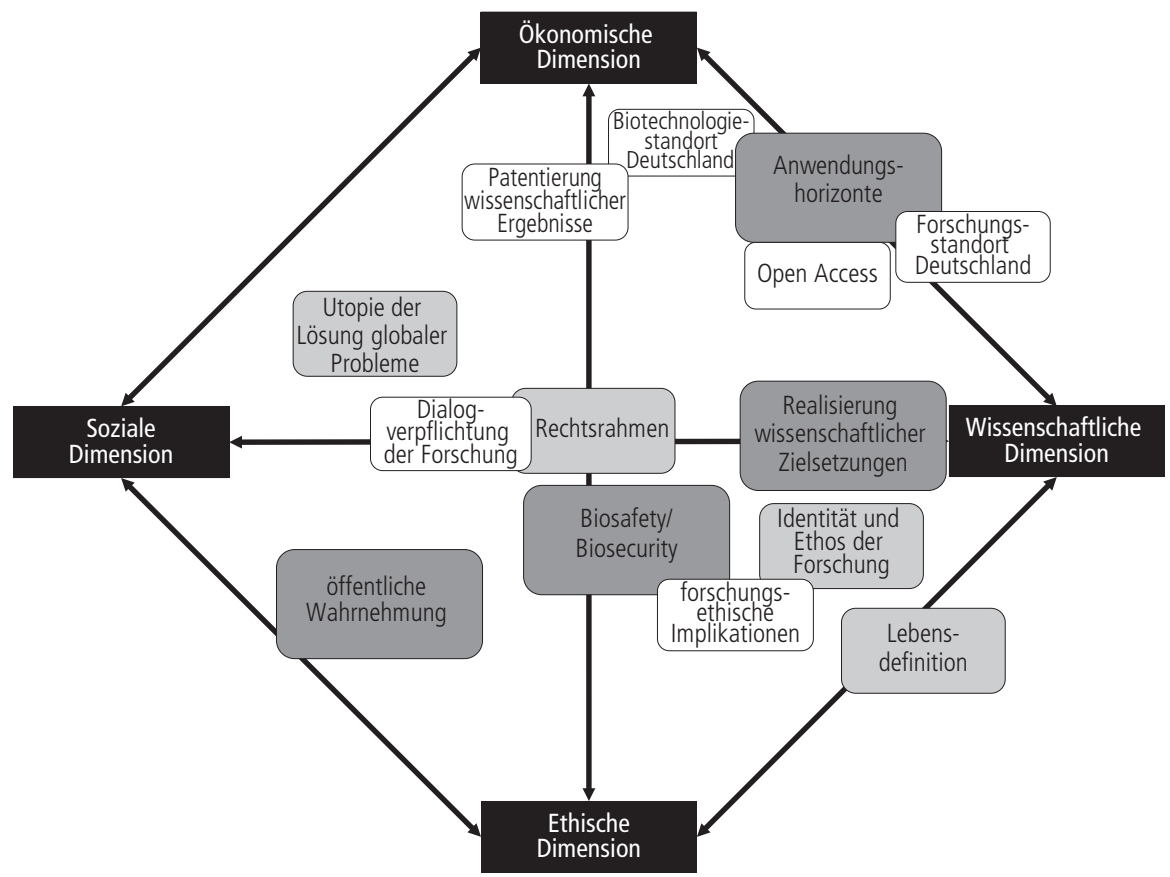

Die ermittelten Problemfelder werden in der Tabelle 1 mittels Thesen inhaltlich beschrieben und eingegrenzt. Ihre tabellarische Listung ergibt sich aus ihrer Verortung innerhalb der gesetzten Leitdimensionen (vgl. Abbildung 1). Den Problemfeldern sind in einem zweiten Schritt ausschließlich diejenigen Indikatoren zugeordnet, die sie real quantitativ ausleuchten können und die im Folgenden in standardisierten Datenblättern aufbereitet sind. Dabei ist zu beachten, dass die unterschiedlichen Problemfelder zum einen in Abhängigkeit vom zugrunde liegenden Sachverhalt unterschiedlich mit Indikatoren gefüllt werden können, zum anderen sind nicht für alle denkbaren Indikatoren für ein spezifisches Problemfeld tatsächlich belastbare und transparente Daten zugänglich. Da die IAG primär auf externe Daten zurückgreift, kann zudem kein Einfluss auf Modus und Intervall ihrer Erhebung genommen werden - mit entsprechenden Konsequenzen für die Fortschreibung. Berücksichtigt werden allgemein also nur diejenigen Problemfelder, die sich quantitativ präzisieren lassen. Die hier nicht mit Indikatoren ausgeleuchteten Aspekte müssen qualitativ beschrieben werden und gehen, wo möglich, im entsprechenden Kapitel auf. in den jeweiligen Texten auf. 
Tabelle 1: Problemfelder zur synthetischen Biologie in Deutschland und Indikatoren zu ihrer Beschreibung

\begin{tabular}{|c|c|c|}
\hline Problemfeld & These & Indikatoren \\
\hline \multicolumn{3}{|c|}{ im Kreuzfeld aller Dimensionen } \\
\hline Rechtsrahmen & $\begin{array}{l}\text { Der rechtliche Rahmen auf nationaler und } \\
\text { europäischer Ebene bestimmt über die } \\
\text { Zulässigkeit von gentechnischen Verfahren und } \\
\text { definiert ihren Einsatz in der wissenschaftli- } \\
\text { chen Praxis bzw. formuliert dafür notwendige } \\
\text { Rahmenbedingungen. Er hat eine Funktion bei } \\
\text { der Vermittlung von einander widersprechen- } \\
\text { den Interessen und Schutzgütern. Die zurzeit } \\
\text { noch unscharfe Abgrenzung der synthetischen } \\
\text { Biologie zur bekannten Gentechnologie } \\
\text { verlangt eine Auseinandersetzung mit den } \\
\text { gegenwärtigen nationalen wie transnationa- } \\
\text { len gesetzlichen Rahmenbedingungen, um } \\
\text { dauerhaft einen sicheren Umgang mit der noch } \\
\text { jungen Forschungsdisziplin gewährleisten zu } \\
\text { können. }\end{array}$ & $\begin{array}{l}\text { Deutsche Stellungnahmen zur Rege- } \\
\text { lungsnotwendigkeit der synthetischen } \\
\text { Biologie (GD-08) }\end{array}$ \\
\hline
\end{tabular}

Wissenschaftliche Dimension

\begin{tabular}{|l|l|}
\hline $\begin{array}{l}\text { Identität und } \\
\text { Ethos der }\end{array}$ & $\begin{array}{l}\text { Die synthetische Biologie fördert ein im } \\
\text { Vergleich zur etablierten gentechnologischen } \\
\text { Forschung anders gestaltetes Verständnis } \\
\text { von Wissenschaft. Dieses bezieht sich auf die } \\
\text { Struktur, die Ausrichtung und Organisation } \\
\text { des Faches. }\end{array}$ \\
\hline $\begin{array}{l}\text { Realisierung } \\
\text { wissenschaft- } \\
\text { licher Zielset- } \\
\text { zungen }\end{array}$ & $\begin{array}{l}\text { Wissenschaftliche Forschung will neue } \\
\text { Erkenntnisse und Technologien generieren. Zu } \\
\text { ihrem Wesen gehört eine begrenzte Planbar- } \\
\text { keit und Ergebnisoffenheit. Nichtdestotrotz } \\
\text { beeinflussen die vorhandenen Rahmenbedin- } \\
\text { gungen - wie die wissenschaftliche Infrastruk- } \\
\text { tur, Förderungsmöglichkeiten oder geltendes } \\
\text { Recht - die Realisierung von gesetzten } \\
\text { Forschungszielen, die sich quantifizierbar z. B. } \\
\text { in Veröffentlichungen, Forschungspreisen oder } \\
\text { akademischen Abschlüssen niederschlagen. }\end{array}$
\end{tabular}

\section{Wissenschaftliche Dimension <> Ethische Dimension}

Biosafety/Biosecurity
Die synthetische Biologie birgt zum einen das Problem, in ihrer Anwendung nichtintendierten Schaden zu verursachen, zum anderen lässt sie sich potenziell zu Missbrauchszwecken verwenden.
Anzahl internationaler Fachartikel zur synthetischen Biologie (SB-01) EU-Fördermaßnahmen (FP6/FP7) für die synthetische Biologie mit ausgewiesener deutscher Beteiligung (SB-05) Fördermaßnahmen der DFG für die synthetische Biologie (SB-10)* 


\begin{tabular}{|c|c|c|}
\hline Problemfeld & These & Indikatoren \\
\hline $\begin{array}{l}\text { forschungsethi- } \\
\text { sche Implika- } \\
\text { tionen }\end{array}$ & $\begin{array}{l}\text { Forschung - vor allem in den Biowissenschaf- } \\
\text { ten und verschärft im biomedizinischen Bereich } \\
\text { - generiert Wissen und Anwendungen, die } \\
\text { eine Auseinandersetzung mit etwaigen Konse- } \\
\text { quenzen für den Mensch, die Gesellschaft und } \\
\text { die Umwelt verlangen. Dabei spielen ethische } \\
\text { Fragen genauso eine Rolle wie soziale oder } \\
\text { rechtliche Aspekte, die es gesellschaftlich zu } \\
\text { kommunizieren gilt und die u. U. politischen } \\
\text { Handlungsbedarf nach sich ziehen. Die Bedeu- } \\
\text { tung des Lebensbegriffs für die synthetische } \\
\text { Biologie macht es notwendig zu klären, ob } \\
\text { und unter welchen Voraussetzung „Leben“ im } \\
\text { normativ folgenreichen Sinn zu schützen ist. }\end{array}$ & $\begin{array}{l}\text { BMBF-geförderte Forschung zu Rahmen- } \\
\text { bedingungen (ELSA) für die synthetische } \\
\text { Biologie (GD-06) }\end{array}$ \\
\hline $\begin{array}{l}\text { Lebensdefi- } \\
\text { nition }\end{array}$ & $\begin{array}{l}\text { Die synthetische Biologie hat sich zum Ziel } \\
\text { gesetzt völlig neuartige biologische Systeme } \\
\text { im Labor hervorzubringen. Dabei geht es zum } \\
\text { einen darum, zu klären, was Leben ist und zum } \\
\text { anderen, wie in Folge dessen vom Menschen } \\
\text { entwickelte biologische Systeme hier einzu- } \\
\text { ordnen sind. }\end{array}$ & \\
\hline \multicolumn{3}{|c|}{ Wissenschaftliche Dimension <> Soziale Dimension } \\
\hline $\begin{array}{l}\text { Dialogver- } \\
\text { pflichtung der } \\
\text { Forschung }\end{array}$ & $\begin{array}{l}\text { Vertreter der synthetischen Biologie legen } \\
\text { sich fest auf die Notwendigkeit, ethische und } \\
\text { gesellschaftliche Aspekte der neuen Tech- } \\
\text { nologien frühzeitig in einem wechselseitigen } \\
\text { Austausch zwischen Gesellschaft, Politik und } \\
\text { Wissenschaft mitzutragen. }\end{array}$ & $\begin{array}{l}\text { Öffentliche Veranstaltungen zur synthe- } \\
\text { tischen Biologie in Deutschland (GD-07) }\end{array}$ \\
\hline \multicolumn{3}{|c|}{ Wissenschaftliche Dimension <> Ökonomische Dimension } \\
\hline $\begin{array}{l}\text { Anwendungs- } \\
\text { horizonte }\end{array}$ & $\begin{array}{l}\text { Anwendungshorizonte werden bereits heute } \\
\text { diskutiert, sind aber in der Praxis bislang } \\
\text { noch nicht realisiert. Sie schließen gleichfalls } \\
\text { visionäre Ziele mit hohem Innovationspotenzial } \\
\text { ein, deren Durchführbarkeit dementsprechend } \\
\text { ungewiss ist. Die Anwendungsmöglichkeiten } \\
\text { der synthetischen Biologie versprechen sehr } \\
\text { weitgefächert zu sein: Die Visionen spannen } \\
\text { von "maßgeschneiderten“ Mikroorganismen, } \\
\text { die z. B. Medikamente, nachwachsende } \\
\text { Rohstoffe oder innovative Biomaterialien } \\
\text { produzieren werden bis hin zur Gestaltung von } \\
\text { gänzlich neuartigen biologischen Systemen } \\
\text { oder der "Wiederbelebung” ausgestorbener } \\
\text { Tierarten wie dem Mammut. }\end{array}$ & $\begin{array}{l}\text { Internationale Beteiligung am iGEM- } \\
\text { Wettbewerb (SB-04) }\end{array}$ \\
\hline
\end{tabular}




\begin{tabular}{|c|c|c|}
\hline Problemfeld & These & Indikatoren \\
\hline $\begin{array}{l}\text { Biotechnolo- } \\
\text { giestandort } \\
\text { Deutschland }\end{array}$ & $\begin{array}{l}\text { Die synthetische Biologie wird gegenwärtig } \\
\text { als wichtige Komponente einer zukünftigen } \\
\text { wissensbasierten Bioökonomie in Deutschland } \\
\text { beworben. }\end{array}$ & \\
\hline $\begin{array}{l}\text { Forschungs- } \\
\text { standort } \\
\text { Deutschland }\end{array}$ & $\begin{array}{l}\text { Die internationale Attraktivität eines For- } \\
\text { schungsstandortes hängt von einer Vielzahl } \\
\text { an Faktoren ab, z. B. der vorhandenen } \\
\text { wissenschaftlichen Infrastruktur, dem Ausmaß } \\
\text { und der Art an Fördermaßnahmen oder auch } \\
\text { von nationalen rechtlichen Regelungen, die } \\
\text { die wissenschaftliche Praxis beeinflussen. Der } \\
\text { internationale Ruf und die Vernetzung inner- } \\
\text { halb der globalisierten Forschungslandschaft } \\
\text { spielen ebenfalls eine Rolle. Für das noch } \\
\text { junge Forschungsgebiet der synthetischen } \\
\text { Biologie benötigt Deutschland eine gesicherte } \\
\text { Förderung von Forschung und Ausbildung } \\
\text { des wissenschaftlichen Nachwuchses, um im } \\
\text { internationalen Vergleich erfolgreich zu sein. }\end{array}$ & $\begin{array}{l}\text { Anzahl internationaler Fachartikel zur } \\
\text { synthetischen Biologie (SB-01) } \\
\text { Internationale Beteiligung am iGEM- } \\
\text { Wettbewerb (SB-04) } \\
\text { EU-Fördermaßnahmen (FP6/FP7) für die } \\
\text { synthetische Biologie mit ausgewiese- } \\
\text { ner deutscher Beteiligung (SB-05) } \\
\text { Fördermaßnahmen der DFG für die } \\
\text { synthetische Biologie (SB-10)* }\end{array}$ \\
\hline Open Access & $\begin{array}{l}\text { Die synthetische Biologie strebt ein Höchstmaß } \\
\text { an Transparenz ebenso an wie freien Zugang } \\
\text { zu Daten, Materialien und Methoden an. }\end{array}$ & \\
\hline \multicolumn{3}{|c|}{ Ethische Dimension $<>$ Soziale Dimension } \\
\hline $\begin{array}{l}\text { öffentliche } \\
\text { Wahrnehmung }\end{array}$ & $\begin{array}{l}\text { Der Einsatz und die Etablierung neuer techno- } \\
\text { logischer Verfahren hängen zentral von deren } \\
\text { gesellschaftlicher Wahrnehmung ab. Sie zeigen } \\
\text { zudem, welche Hoffnungen und Befürchtungen } \\
\text { diesbezüglich in der Bevölkerung kursieren. }\end{array}$ & $\begin{array}{l}\text { Printmediale Abbildung des Themenbe- } \\
\text { reichs synthetische Biologie (SB-02) } \\
\text { Neuerscheinungen zum Themenbereich } \\
\text { synthetische Biologie (SB-03) } \\
\text { Öffentliche Veranstaltungen zur synthe- } \\
\text { tischen Biologie in Deutschland (GD-07) } \\
\text { Internetpräsenz zum Stichwort syntheti- } \\
\text { sche Biologie (SB-09) } \\
\text { Öffentliche Wahrnehmung der syntheti- } \\
\text { schen Biologie im EU-Raum (SB-11)* }\end{array}$ \\
\hline \multicolumn{3}{|c|}{ Soziale Dimension <>0̈konomische Dimension } \\
\hline $\begin{array}{l}\text { Patentierung } \\
\text { wissenschaftli- } \\
\text { cher Ergebnisse }\end{array}$ & $\begin{array}{l}\text { Patente sind in anwendungsnahen Disziplinen } \\
\text { ein Ausdruck innovativen Forschungsgesche- } \\
\text { hens. Sie stellen in besonderem Maß eine } \\
\text { Vernetzung von Wissenschaft und Wirtschaft } \\
\text { dar, die durchaus nicht spannungsfrei ist. Bei } \\
\text { Biopatenten, die Organismen oder Teile von } \\
\text { ihnen wie z. B. einzelne Gene betreffen, stellt } \\
\text { sich zudem die Frage, inwiefern und in welcher } \\
\text { Form Leben kommodifiziert werden kann. }\end{array}$ & \\
\hline
\end{tabular}




\begin{tabular}{|l|l|l|}
\hline Problemfeld & These & Indikatoren \\
\hline Utopie der & Gegenwärtig kursieren visionäre Vorstellungen & \\
Lösung globaler & bezüglich zukünftiger Potenziale der synthe- & \\
Probleme & $\begin{array}{l}\text { tischen Biologie. Diese versprechen globale } \\
\text { Problemlagen wie zum Beispiel Nahrungsmit- } \\
\text { telknappheit lösen zu können. }\end{array}$ & \\
& & \\
\hline
\end{tabular}

Die fett markierten Indikatoren werden nachfolgend anhand detaillierter Datenblätter vorgestellt und grafisch aufbereitet; * kennzeichnet neue Indikatoren im Vergleich zur letzten Veröffentlichung der Daten (vgl. Köchy/Hümpel, 2012:257-285).

Empirische Daten werden weiterhin für das Monitoring nur sichtbar, insofern sie dezidiert dem „Label“ der synthetischen Biologie zugeordnet sind. Alle bereits vorhandenen Indikatoren wurden im vorliegenden Bericht weitergeführt, zum Teil in überarbeiteter Darstellung in Anpassung an die zunehmende Datenbasis und sich abzeichnende Entwicklungstrends (SB-01, SB-04, SB-07). Für einen Indikator (SB-08) hat sich die zugrunde gelegte Datenbasis seit der letzten Erhebung verändert, was eine Angleichung des Erhebungsmodus notwendig machte. Darüber hinaus wurden - mit Blick auf die von der IAG angestrebte Vereinheitlichung von themenübergreifenden Indikatoren ausgewählte Indikatoren (SB-03, SB-05, SB-09) grundsätzlich aktualisiert. Zudem konnte die Datenbasis im vorliegenden Bericht erweitert werden: So konkretisiert nun der Indikator SB-10 das Problemfeld Forschungsstandort Deutschland; dem Problemfeld öffentliche Wahrnehmung wird durch den Indikator SB-11 mehr Kontur verliehen.

Mittels standardisierter Datenblätter werden die Indikatoren nachfolgend vorgestellt. Die Rubriken „Abgrenzung der Berechnungsgrößen“ und „Aussagefähigkeit“ bilden dabei, wie auch bei den anderen Themen dieses Bandes, den interpretativen Rahmen. 
Laufende Nr:: SB-01

Problemfeld: Forschungsstandort Deutschland + Realisierung wissenschaftlicher Zielsetzungen

\section{INDIKATOR: ANZAHL INTERNATIONALER FACHARTIKEL ZUR SYNTHETISCHEN BIOLOGIE}

\section{DATENQUELLE:}

Scopus - Abstract- und Zitationsdatenbank. Unter:

www.scopus.com/scopus/home.url

Zugriff: April 2014, Stand: April 2014.

\section{VERFÜGBARKEIT DER DATEN:}

\section{lizenziert}

Die Datenbank "Scopus" wird seit 2004 vom Wissenschaftsverlag Elsevier kostenpflichtig online angeboten. Sie bietet eine umfangreiche Sammlung an bibliografischen Angaben zu weltweiten Fachveröffentlichungen aus den Natur- und Ingenieurwissenschaften, der Medizin sowie den Sozial- und Geisteswissenschaften. Scopus indiziert dabei nur fortlaufende Fachpublikationen mit ISSN-Nummer wie Zeitschriften und Schriftenreihen sowie ausgewählte Informationen zu Fachkonferenzen. Sie wird nach Anbieterangaben täglich aktualisiert und enthielt zum Recherchezeitpunkt ca. 53 Millionen Einträge - davon 51 \% mit zusätzlichen Fachtextinformationen in der Form von »abstracts« (http://www. elsevier.com/online-tools/scopus/content-overview [23.04.2014]). Die Datenbank erlaubt damit eine umfassende, fachübergreifende Recherche von aktuellen Fachpublikationen für verschiedenste Forschungsthemen.

\section{ABGRENZUNG DER BERECHNUNGSGRÖSSEN:}

Für die Recherche relevanter Fachpublikationen wurde das Stichwort "synthetic biology" in Titel, Zusammenfassung und/oder angegebenen Schlagwörtern in der Scopus-Datenbank gesucht. Es wurden für die vorliegende Publikation ausschließlich Fachartikel recherchiert: DOCTYPE(ar). Andere zitierbare Dokumenttypen (Reviews, Short Surveys etc.) sowie nicht zitierfähiges Material wurden nicht mehr erfasst in Anlehnung an den für andere Themen an dieser Stelle verwendeten Recherchemodus (vgl. Indikator GT-03). Alle verfügbaren Dokumente zum verwendeten Stichwort waren dabei für den Recherchezeitraum einem konkreten Dokumenttyp zugeordnet (Daten hier nicht gezeigt). Es wurden alle verfügbaren Fachgebiete (Life Sciences, Health Sciences, Physical Sciences und Soial Sciences \& Humanities) einbezogen. Weiterführend wurden die Autorenschaften nach Ländern ab 2001 - dem Jahr, in dem der Gentechnologiebericht seine Arbeit aufgenommen hat - erfasst.

\section{GLIEDERUNG DER DARSTELLUNG:}

a) Publikationsleistungen im Themenbereich synthetische Biologie: Jährlich veröffentlichte Fachartikel ab 2001

b) Deutsche Publikationsleistungen im internationalen Vergleich: Veröffentlichte Fachartikel (2001-2013)

c) Deutsche Publikationsleistungen im EU-Vergleich: Veröffentlichte Fachartikel (2001-2013)

\section{BERECHNUNGSHÄUFIGKEIT:}

jährlich

\section{AUSSAGEFÄHIGKEIT:}

Der Indikator spiegelt die weltweiten Forschungsaktivitäten auf dem Gebiet der synthetischen Biologie wider. Anhand des Umfangs der veröffentlichten Publikationen kann beobachtet werden, wie intensiv ein Themengebiet über die Jahre beforscht wird und welche Länder jeweils eine Vorrangstellung im „internationalen Forschungswettlauf” einnehmen. Dabei ist zu berücksichtigen, dass gerade das Fachgebiet der synthetischen Biologie durchaus unterschiedlich von seinen Akteuren abgegrenzt wird: Die Einordnung relevanter Veröffentlichungen ohne benannten Bezug zum Fachgebiet stellt eine besondere Schwierigkeit im Rahmen der Indikatorenerhebung für die synthetische Biologie dar. Es werden aktuell nur Fachartikel berücksichtigt, die sich dem Label "synthetic biology" eindeutig zuordnen lassen. Auch kann eine Veröffentlichung eine internationale Kollaboration von Autorinnen und Autoren mehrerer Länder darstellen, die dann entsprechend mehrfach gezählt wird. 
a) Abbildung 2: Publikationsleistungen im Themenbereich synthetische Biologie: Jährlich veröffentlichte Fachartikel ab 2001

500

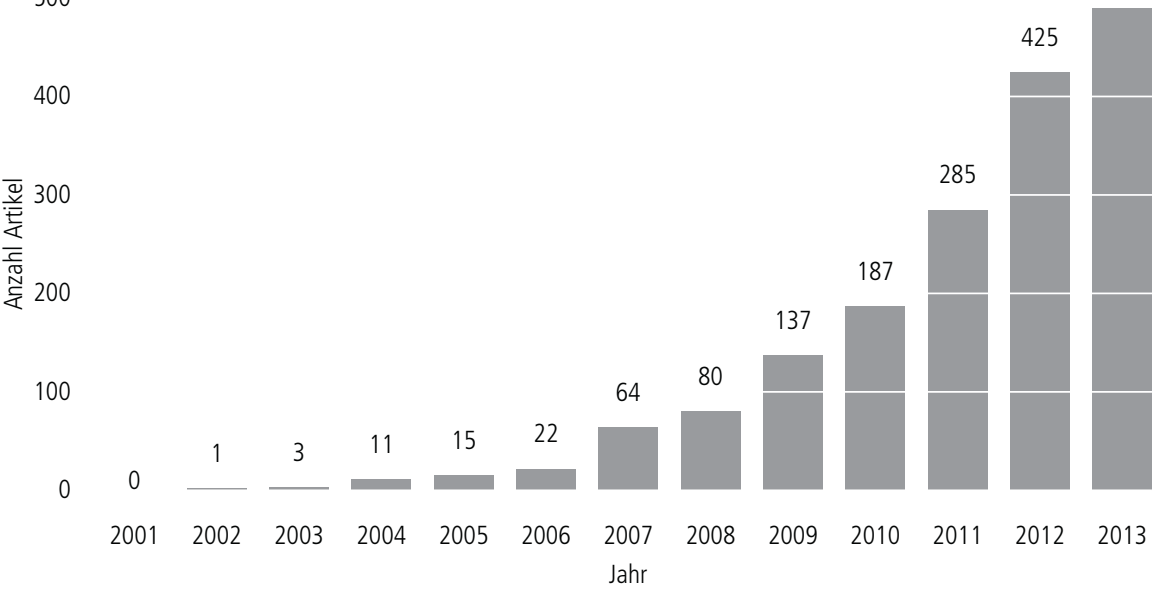

Jeweils aktualisierte Daten; Unterschiede zu früheren Veröffentlichungen möglich. Fachartikel in Scopus-Datenbank zum Suchbegriff »synthetic biology« vor 2001: $N=6$.

Quelle: siehe Indikatorenblatt SB-01.

b) Abbildung 3: Deutsche Publikationsleistungen im internationalen Vergleich: Veröffentlichte Fachartikel (2001-2013)

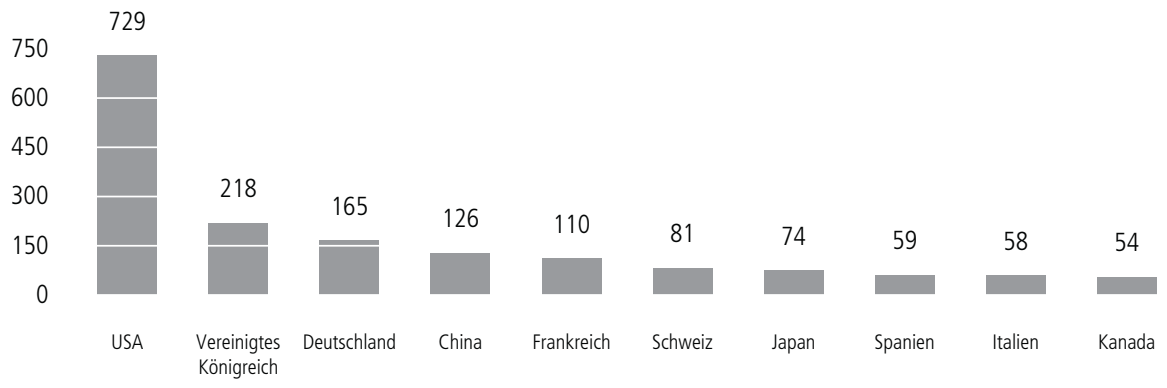

Jeweils aktualisierte Daten; Unterschiede zu früheren Veröffentlichungen möglich.

Quelle: siehe Indikatorenblatt SB-01.5771/9783845246956-408, am 26.04.2023, 10:21:37 
c) Tabelle 2: Deutsche Publikationsleistungen im EU-Vergleich: Veröffentlichte Fachartikel (2001-2013)

\begin{tabular}{|c|c|c|c|c|}
\hline EU-28 & Bevölkerung ${ }^{1)}$ & veröffe & achartikel pro & itraum \\
\hline & & $2001-2004$ & $2005-2008$ & $2009-2013^{21}$ \\
\hline Deutschland & 80.523 .746 & 0 & 18 & 147 \\
\hline Frankreich & 65.633 .194 & 0 & 13 & 97 \\
\hline Vereinigtes Königreich & 63.896 .071 & 0 & 8 & 210 \\
\hline Italien & 59.685 .227 & 0 & 3 & 55 \\
\hline Spanien & 46.704 .308 & 0 & 7 & 52 \\
\hline Polen & 38.533 .299 & 0 & 0 & 7 \\
\hline Rumänien & 20.020 .074 & 0 & 0 & 1 \\
\hline Niederlande & 16.779 .575 & 0 & 2 & 38 \\
\hline Belgien & 11.161 .642 & 0 & 2 & 14 \\
\hline Griechenland & 11.062 .508 & 0 & 0 & 0 \\
\hline Tschechische Republik & 10.516 .125 & 0 & 1 & 3 \\
\hline Portugal & 10.487 .289 & 0 & 0 & 4 \\
\hline Ungarn & 9.908 .798 & 0 & 1 & 6 \\
\hline Schweden & 9.555 .893 & 0 & 1 & 13 \\
\hline Österreich & 8.451 .860 & 0 & 1 & 28 \\
\hline Bulgarien & 7.284 .552 & 0 & 0 & 0 \\
\hline Dänemark & 5.602 .628 & 0 & 0 & 26 \\
\hline Finnland & 5.426 .674 & 0 & 0 & 6 \\
\hline Slowakei & 5.410 .836 & 0 & 0 & 1 \\
\hline Irland & 4.591 .087 & 1 & 0 & 3 \\
\hline Kroatien & 4.262 .140 & 0 & 0 & 1 \\
\hline Litauen & 2.971 .905 & 0 & 0 & 1 \\
\hline Slowenien & 2.058 .821 & 0 & 0 & 5 \\
\hline Lettland & 2.023 .825 & 0 & 0 & 0 \\
\hline Estland & 1.324 .814 & 0 & 0 & 0 \\
\hline Zypern & 865.878 & 0 & 0 & 0 \\
\hline Luxemburg & 537.039 & 0 & 0 & 0 \\
\hline Malta & 421.364 & 0 & 0 & 0 \\
\hline
\end{tabular}

1) Eurostat (http://europa.eu/about-eu/facts-figures/living/index_de.htm [10.12.2013]) 2) Stichtag für Recherche: 23.04.2014.

Jeweils aktualisierte Daten; Unterschiede zu früheren Veröffentlichungen möglich.

Farbschattierung kennzeichnet Umfang an veröffentlichten Fachartikeln:

\section{\begin{tabular}{|l|l|l|l|}
\hline 0 & $\geq 1$ & $\geq 10$ & $\geq 100$ \\
\hline
\end{tabular}}

Quelle: siehe Indikatorblatt SB-01. 
Laufende Nr.: SB-02

Problemfeld: Öffentliche Wahrnehmung

\section{INDIKATOR: PRINTMEDIALE ABBILDUNG DES THEMENBEREICHS SYNTHETISCHE BIOLOGIE}

\section{DATENQUELLE:}

Frankfurter Allgemeine Zeitung. Unter: www.faz.net

Süddeutsche Zeitung. Unter: www.sueddeutsche.de

Die Zeit. Unter: www.zeit.de

Der Spiegel. Unter: www.spiegel.de

Zugriff (alle): August 2014, Stand: August 2014

\section{VERFÜGBARKEIT DER DATEN:}

mehrheitlich öffentlich

Die Recherche in den Online-Archiven der ausgewählten deutschen Zeitungen und Zeitschriften ist mit Ausnahme der Süddeutschen Zeitung (SZ) kostenlos zugänglich. Beiträge zu ausgewählten Suchbegriffen können hier tagesaktuell recherchiert werden, jedoch können die Presseartikel der Frankfurter Allgemeinen Zeitung (F.A.Z.) mehrheitlich nur kostenpflichtig abgerufen werden.

\section{ABGRENZUNG DER BERECHNUNGSGRÖSSEN:}

Für die Recherche relevanter Printartikel wurde das Stichwort "synthetische Biologie" im Volltext ab 2001 (Beginn der IAG Gentechnologiebericht) überregional gesucht. Ausschließlich online erschienene Presseartikel, Artikel in Sonderheften sowie regionale und in anderen Medien erschienene Beiträge wurden dabei nicht berücksichtigt. Es wurde keine weiterführende qualitative Filterung der Suchergebnisse vorgenommen.

\section{GLIEDERUNG DER DARSTELLUNG:}

Anzahl an Printartikeln zum Stichwort "synthetische Biologie"

\section{BERECHNUNGSHÄUFIGKEIT:}

jährlich

\section{AUSSAGEFÄHIGKEIT:}

Der Indikator dokumentiert die Dichte der öffentlichen Berichterstattung zum Themenbereich im dargestellen Zeitraum in ausgewählten überregionalen Printmedien. Diese erreichen - das dokumentieren die Auflagezahlen - eine Vielzahl an Menschen in ganz Deutschland, die sich auf diesem Weg über den Themenbereich informieren können. 
Abbildung 4: Anzahl an Printartikeln zum Stichwort "synthetische Biologie"

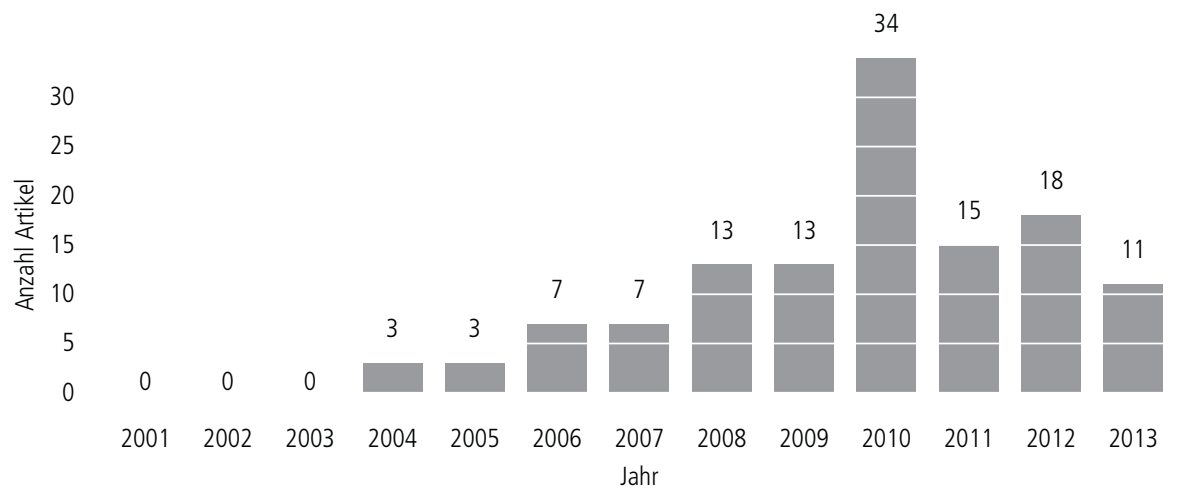

Quelle: siehe Indikatorenblatt SB-02. 
Laufende Nr.: SB-03

Problemfeld: Öffentliche Wahrnehmung

\section{INDIKATOR: NEUERSCHEINUNGEN ZUM THEMENBEREICH SYNTHETISCHE BIOLOGIE}

\section{DATENQUELLE:}

Online-Katalog der Deutschen Nationalbibliothek. Unter:

https://portal.dnb.de

Zugriff: August 2014, Stand: k. A.

\section{VERFÜGBARKEIT DER DATEN:}

\section{öffentlich}

Die Nationalbibliothek (DNB) ist eine bundesunmittelbare Anstalt des öffentlichen Rechts. Ihre Aufgabe ist die Archivierung und bibliografische Erfassung in Deutschland veröffentlichter Medienwerke (Monografien, Zeitungen, Zeitschriften, Loseblattwerke, Karten, Musikalien, Tonträger, elektrische Publikationen). Darüber hinaus werden auch im Ausland veröffentlichte deutschsprachige Medienwerke, im Ausland veröffentlichte Übersetzungen deutschsprachiger Medienwerke, fremdsprachige Medienwerke über Deutschland sowie Exilpublikationen deutschsprachiger Emigranten zwischen 1933 und 1950 erfasst. Seit 2006 werden zusätzlich Online-Publikationen systematisch berücksichtigt. Der Katalog der Deutschen Nationalbibliothek erlaubt eine kostenlose Recherche innerhalb der umfassenden Bibliotheksbestände seit 1913. Nach Anbieterangaben werden eingegangene Publikationen mit einer Bearbeitungszeit von ca. einem Monat in den Katalog und in die Deutsche Nationalbibliografie eingetragen.

\section{ABGRENZUNG DER BERECHNUNGSGRÖSSEN:}

Für die Recherche relevanter Titel wurde der Suchbegriff "synthetische Biologie" im Modus „Expertensuche” im gesamten Bestand des Katalogs der Deutschen Nationalbibliolthek ab 2001 (Beginn des Gentechnologieberichts) gesucht. Da es sich um eine Suche nach einem speziellen Begriff handelt, wurde über die Titelfelder hinausgehende Suchfunktion (Index=woe) verwendet. Im Bestand vermerkte Hochschulschriften wurden explizit ausgenomen, da sie für den interessierten Laien schwer zugänglich sind. Generell ausgeschlossen wurden Periodika sowie Normdaten für einzelne Personen, Organisationen, Veranstaltungen, Geografika, Sachbegriffe und Werktitel, die im Katalog der DNB geführt werden. Es wurde keine weiterführende qualitative Filterung der Suchergebnisse vorgenommen.

\section{GLIEDERUNG DER DARSTELLUNG:}

Anzahl an Neuerscheinungen zum Themenbereich synthetische Biologie

\section{BERECHNUNGSHÄUFIGKEIT:}

jährlich

\section{AUSSAGEFÄHIGKEIT:}

Der Indikator dokumentiert die publizistische Dichte für den Themenbereichs. Er zählt diejenigen Materialien, die auch der interessierten Öffentlichkeit frei zur Verfügung stehen. Über die (etwa in Fachjournalen geführte) wissenschaftsinterne Aushandlung liefert er keine Aussage. 
Abbildung 5: Anzahl an Neuerscheinungen zum Themenbereich synthetischen Biologie

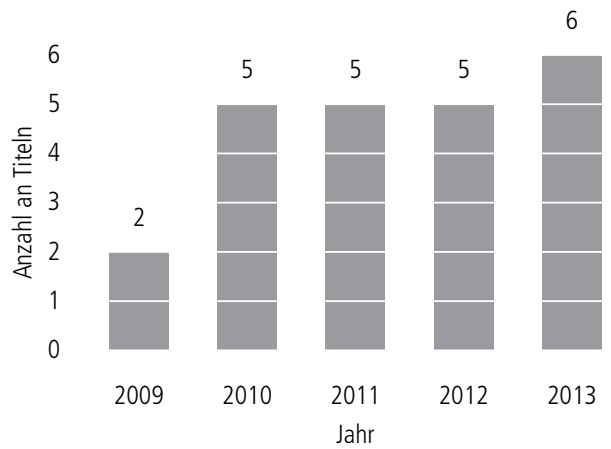

Erfassung der im DNB-Katalog verzeichneten Titel bis zum Stichtag am 06.08.2014. Erweiterter Recherchemodus; Unterschiede zu früheren Veröffentlichungen möglich.

Quelle: siehe Indikatorenblatt SB-03. 
Laufende Nr.: SB-04

Problemfeld: Forschungsstandort Deutschland + Anwendungshorizonte

\section{INDIKATOR: INTERNATIONALE BETEILIGUNG AM IGEM-WETTBEWERB}

\section{DATENQUELLE:}

iGEM 2004. Unter: http://igem.org/Results?year=2004

iGEM 2005. Unter: http://igem.org/Results?year=2005

iGEM 2006. Unter: http://2006.igem.org/wiki/index.php/Jamboree

iGEM 2007. Unter: http://igem.org/Results?year=2007

iGEM 2008. Unter: http://igem.org/Results?year=2008

iGEM 2009. Unter: http://igem.org/Results?year=2009

iGEM 2010. Unter: http://igem.org/Results?year $=2010$

iGEM 2011. Unter: http://igem.org/Results?year=2011

iGEM 2012. Unter: http://igem.org/Results?year $=2012$

iGEM 2013: http://igem.org/Results?year=2013

Zugriff (alle): April 2014, Stand: Dezember des jeweiligen Wettbewerbjahres

\section{VERFÜGBARKEIT DER DATEN:}

\section{öffentlich}

Unter dem Titel „iGEM" (international Genetically Engineered Machine) wird im Forschungsfeld der Synthetischen Biologie jährlich zu einem internationalen Wettbewerb für Universitätsstudierende aufgerufen. Die studentischen Teams sind angehalten, selbstständig an innovativen Ideen zu arbeiten und experimentell geeignete DNA-Konstrukte (sogenannte Biobricks) im Labor dafür herzustellen. Die besten Teams aus aller Welt (jeweils ausgewählt in regionalen Vorentscheiden) stellen ihre Arbeiten dann am Jahresende in einem Finale in Boston vor. Der Internetauftritt des iGEM-Wettbewerbs ist online unter http://ung.igem.org frei zugänglich und bietet eine Fülle an Informationen für die teilnehmenden studentischen Teams aus aller Welt. Die Teams haben die Möglichkeit, ihre Projekte ausführlich online vorzustellen. Sowohl der aktuelle als auch die vergangenen Wettbewerbe seit 2004 sind einsehbar.

\section{ABGRENZUNG DER BERECHNUNGSGRÖSSEN:}

Die für den iGEM-Wettbewerb registrierten studentischen Teams wurden nach Ländern unter der Rubrik "jamboree results” für die einzelnen Jahre recherchiert. Teams, die ihre Teilnahme vor Abschluss des Wettbewerbs zurückgezogen hatten ( "withdrew"), wurden nicht berücksichtigt. Es muss darauf hingewiesen werden, dass das Wettbewerbsformat sowie der Internetauftritt von den Veranstaltern ständig weiterentwickelt werden. Für die Jahre 2004 bis 2006 stehen weniger Daten zur Verfügung als für die folgenden Jahre. Für das Jahr 2006 wurde deshalb auf zusätzliche Daten auf der oben angegebenen Webseite zurückgegriffen. 2011 wurden regionale Vorentscheide vor dem finalen Wettbewerb in Boston („world championship") eingeführt: Der Indikator zählt weiterhin alle Teams, die ein iGEM-Projekt erstellt haben (Abb. $a$ und b) sowie auch die Qualifizierung für das Finale für ausgewählte Länder aus (Abb. c). Ab 2011 werden zudem schulische Teams ( „high school division“) separat vom eigentlichen Wettbewerb bewertet: Der Indikator konzentriert sich weiterhin auf die Abbildung der universitären Nachwuchsförderung ( „collegiate division“). Die Daten werden hier ab 2004 - dem Beginn des iGEM-Wettbewerbs - dargestellt. Die Abbildungen wurden im Vergleich zu vorangegangenen Publikationen in Anpassung an das wechselnde Wettbewerbsformat sowie die zunehmende Datenmenge modifiziert und erweitert.

\section{GLIEDERUNG DER DARSTELLUNG:}

a) Studentische Teams im iGEM-Wettbewerb seit 2004

b) Internationale Beteiligung am iGEM-Wettbewerb seit 2004 (in Prozent)

c) iGEM-Teams 2013 (Finale) 


\section{BERECHNUNGSHÄUFIGKEIT:}

jährlich

\section{AUSSAGEFÄHIGKEIT:}

Der Indikator kann als Indiz für das weltweite Interesse der Nachwuchswissenschaftler an der synthetischen Biologie herangezogen werden. Anhand der Teilnahme an diesem renommierten studentischen Wettbewerb, der für das Fachgebiet einzigartig ist, kann beobachtet werden, wie erfolgreich Deutschland im internationalen Vergleich vertreten ist. Es sollte hier berücksichtigt werden, dass einzelne Länder aufgrund ihrer Wissenschaftslandschaft und Prosperität mit weniger Projekten antreten können als andere, was keine Aussage zur Qualität einzelner studentischer Teams darstellt.

a) Abbildung 6: Studentische Teams im iGEM-Wettbewerb seit 2004

200

Anzahl teilnehmender iGEM-Teams

$\longrightarrow$ Anzahl beteiligter Länder

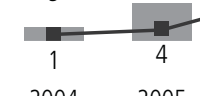

14 
b) Abbildung 7: Internationale Beteiligung am iGEM-Wettbewerb seit 2004 (in Prozent)

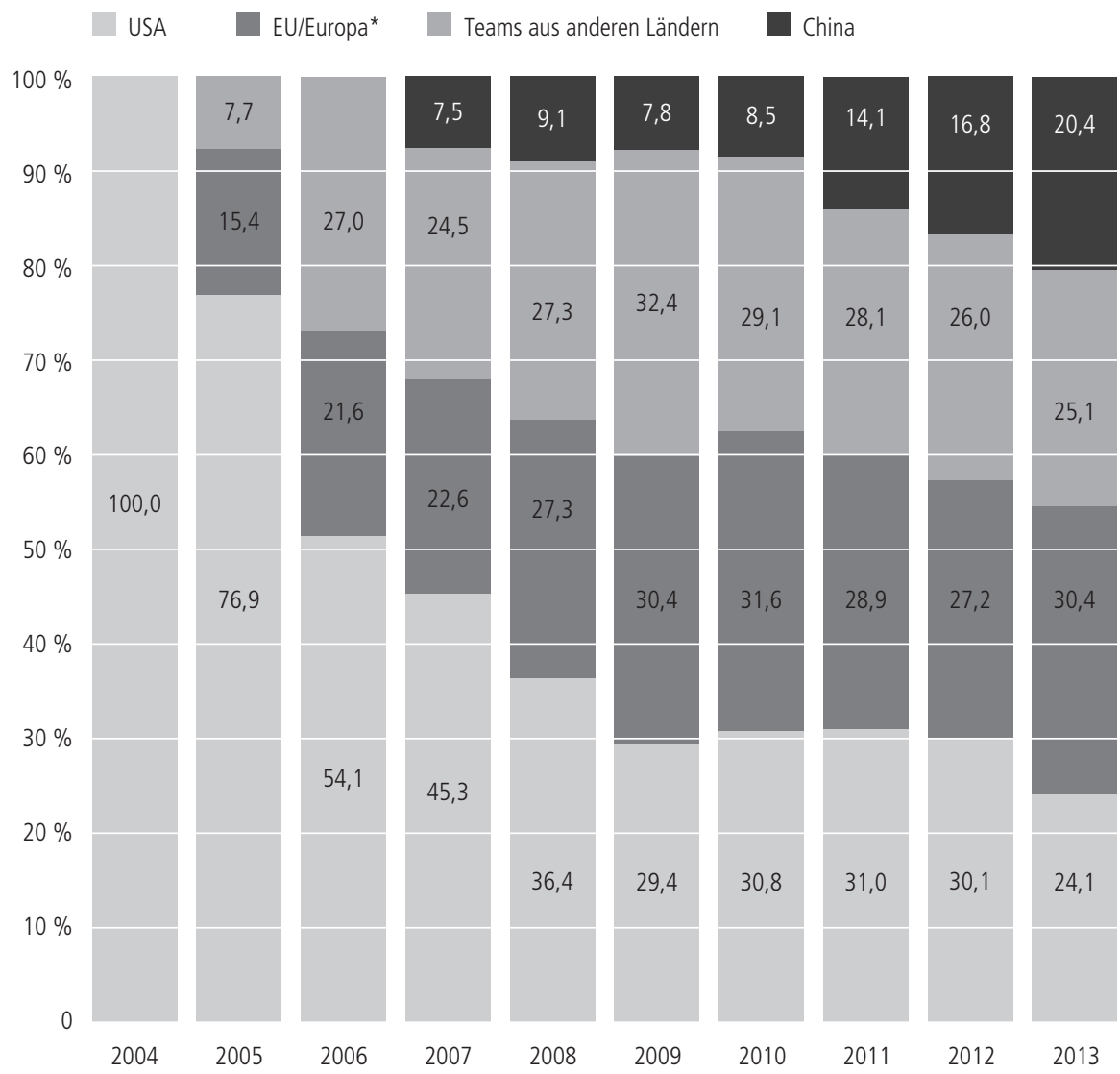

* EU-Mitgliedstaaten und Kandidatenländer sowie andere europäische Länder unter: http://europa.eu/about-eu/countries/index_de.htm [28.04.2014]. Jeweils aktualisierte Daten; Unterschiede zu früheren Veröffentlichungen möglich. Studentische Teams aus Deutschland: $\mathrm{N}=0$ für 2005; N = 1 für 2006 (2,7 \% Anteil bezogen auf alle iGEM-Teams in diesem Jahr); $N=1$ für 2007 (1,9\%); N = 2 für 2008 (2,6\%); $N=4$ für $2009(3,9 \%) ; N=8$ für $2010(6,8 \%) ; N=5$ für 2011 (3,5\%); N = 11 für $2012(6,4 \%) ; N=11$ für $2013(5,8 \%)$.

Quelle: siehe Indikatorenblatt SB-04. 
c) Abbildung 8: iGEM-Teams 2013 (Finale)

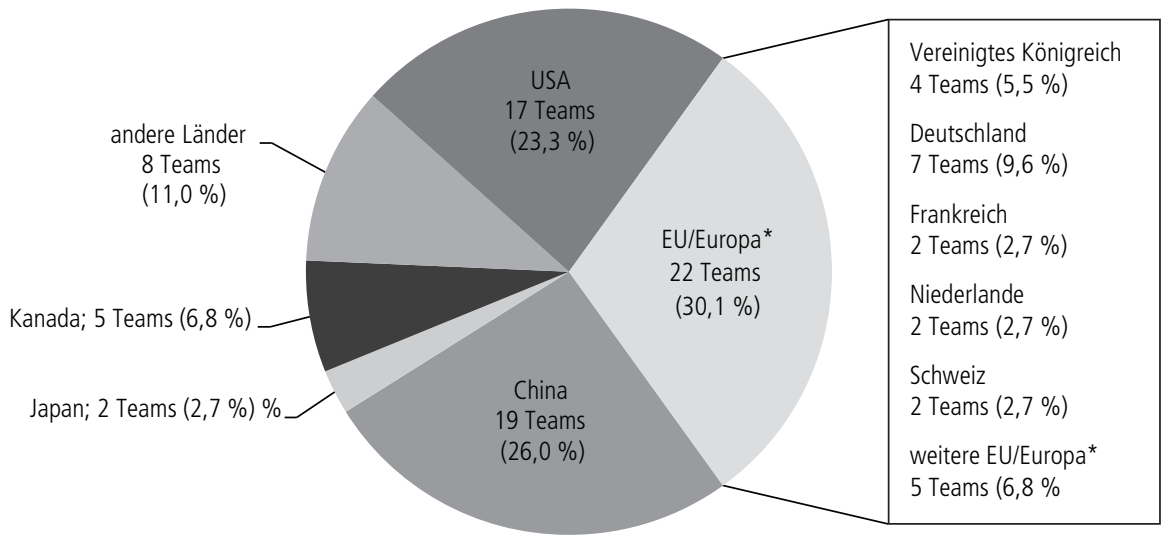

* EU-Mitgliedstaaten und Kandidatenländer sowie andere europäische Länder unter: http://europa.eu/about-eu/ countries/index_de.htm [28.04.2014]: Dänemark, Belgien, Italien, Schweden und Spanien jeweils N = 1.

Quelle: siehe Indikatorenblatt SB-04. 
Laufende Nr:: SB-05

Problemfeld: Forschungsstandort Deutschland + Realisierung wissenschaftlicher Zielsetzungen

\section{INDIKATOR: EU-FÖRDERMASSNAHMEN (FP6/FP7) FÜR DIE SYNTHETISCHE BIOLOGIE MIT} AUSGEWIESENER DEUTSCHER BETEILIGUNG

\section{DATENQUELLE:}

CORDIS - Forschungs- und Entwicklungsinformationsdienst der Gemeinschaft. Unter:

http://cordis.europa.eu/projects/home_de.html

Zugriff: April 2014, Stand: siehe einzelne Projektbeschreibungen in CORDIS.

\section{VERFÜGBARKEIT DER DATEN:}

öffentlich

CORDIS ist eine Internetplattform, die über die Fördermaßnahmen der Europäischen Union (EU) im Bereich Forschung und Entwicklung informiert. Es ist die wichtigste Informationsquelle für EU-finanzierte Projekte seit 1990. Der Zugang ist kostenlos. Über CORDIS werden u. a. die aktuellen Rahmenprogramme für Forschung und technologische Entwicklung der EU umgesetzt.

\section{ABGRENZUNG DER BERECHNUNGSGRÖSSEN:}

Für die Recherche relevanter EU-geförderter Projekte wurde das Stichwort „synthetic biology“ in der CORDIS-Datenbank gesucht. Es wurden nur Suchergebnisse berücksichtigt, die Deutschland als Koordinator bzw. Teilnehmer ausweisen. Es wurde keine weiterführende qualitative Filterung der Suchergebnisse vorgenommen. Die aufgeführten Detailinformationen der einzelnen Projekte wurden den verlinkten Projektbeschreibungen auf CORDIS entnommen. Die Suche wurde auf das 6. (2002-2007) und 7. (2007-2013) Forschungsrahmenprogramm der EU beschränkt, die die gegenwärtige Laufzeit des Gentechnologieberichts abdecken.

\section{GLIEDERUNG DER DARSTELLUNG:}

a) EU-geförderte Forschungsprojekte in FP6/FP7

b) Höhe der EU-Förderung (in Mio. Euro) in FP6/FP7

\section{BERECHNUNGSHÄUFIGKEIT:}

jährlich

\section{AUSSAGEFÄHIGKEIT:}

Die Forschungsrahmenprogramme können als wichtigstes Instrument der Europäischen Union zur Förderung von Forschungs- und Entwicklungsmaßnahmen verstanden werden. Das Ausmaß der Forschungsförderung durch die EU erlaubt Rückschlüsse auf das wissenschaftliche und wirtschaftliche Potenzial eines Themenbereichs, das auf europäischer Ebene antizipiert wird. Zu einer umfassenden Beurteilung ist eine langfristige Beobachtung angezeigt. Zudem sind in diesem Zusammenhang weitere Quellen der Forschungsfinanzierung zu berücksichtigen. 
a) Abbildung 9: EU-geförderte Forschungsprojekte in FP6/FP7

\section{FP6}

EUROBIOSYN

SYNBIOLOGY

NANOMOT

PROBACTYS

EMERGENCE

TESSY

SYNTHCELLS

CELLCOMPUT

\section{FP7}

TARPOL

NMU-LIPIDS

SYNTH-ETHICS

EVOBODY

COMPBIOMAT

DNA MACHINES

RYSBIPNC

FUME

KYROBIO

PROMYSE

EST-FRAME

ERASYNBIO

SYNAD

CYANOFACTORY

SOFI

N-ABLE

SYN-ENERGENE

YEASTCELL

SYNPEPTIDE

RIBONETS

QUANTFUNG

TAMPTING

SYNSIGNAL

PROMYS

MIPDESIGN

SAGE

FLUOR21 $\leq 1$ Mio Euro

$\leq 2$ Mio Euro

$\leq 5$ Mio Euro

$\leq 10$ Mio Euro

$>10$ Mio Euro

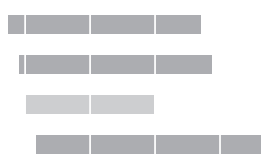

$+1$

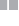
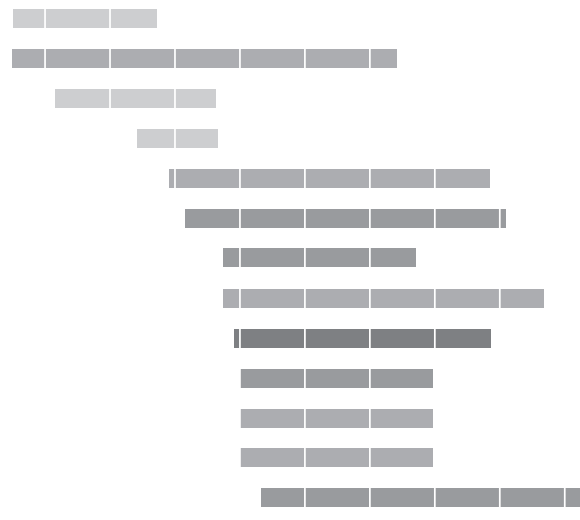

In
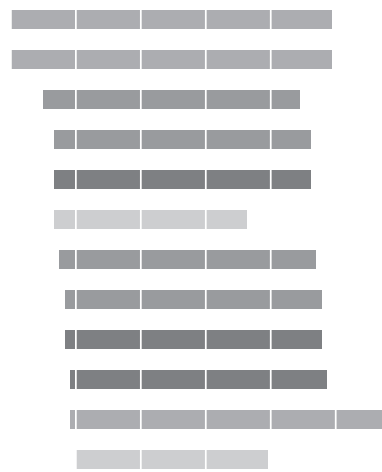

Jan. Jan. Jan. Jan. Jan. Jan. Jan. Jan. Jan. Jan. Jan. Jan. Jan. Jan. Jan.

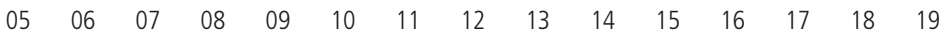

Jeweils aktualisierte Daten; Unterschiede zu früheren Veröffentlichungen möglich.

Quelle: siehe Indikatorenblatt SB-05. 
b) Abbildung 10: Höhe der EU-Förderung (in Mio. Euro) in FP6/FP7

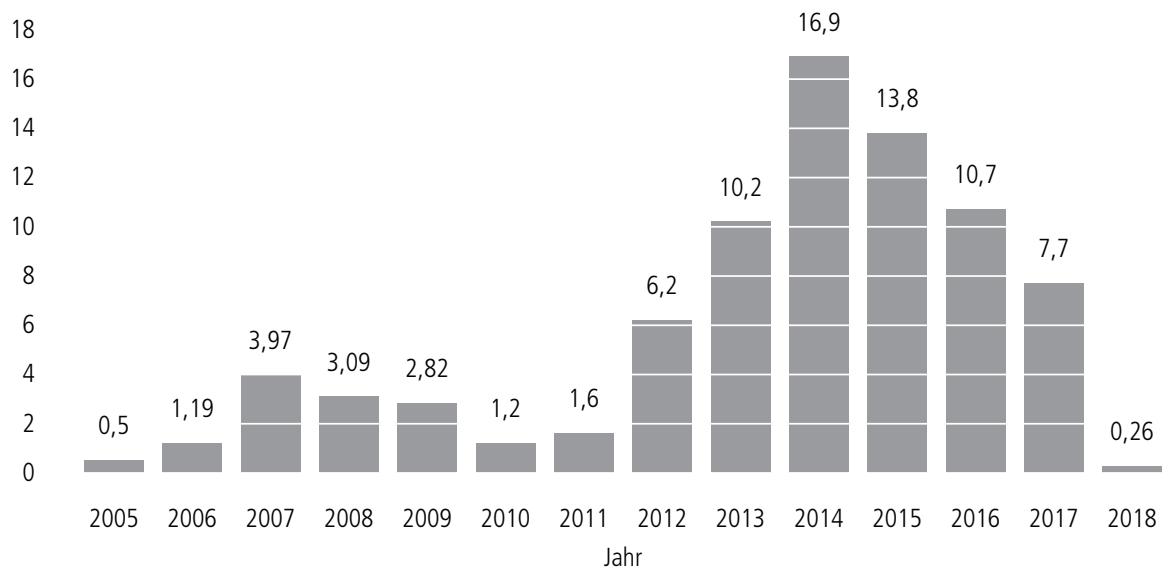

Quelle: siehe Indikatorenblatt SB-05. 
Laufende Nr:: SB-06

Problemfeld: Forschungsethische Implikationen + Biosafety/Biosecurity

\section{INDIKATOR: BMBF-GEFÖRDERTE FORSCHUNG ZU RAHMENBEDINGUNGEN (ELSA) FÜR DIE} SYNTHETISCHE BIOLOGIE

\section{DATENQUELLE:}

Online-Förderkatalog der Bundesregierung. Unter:

http://foerderportal.bund.de/foekat

Zugriff: April 2014, Stand: k. A.

\section{VERFÜGBARKEIT DER DATEN:}

öffentlich

Der Förderkatalog der Bundesregierung stellt eine digitale Datenbank für die Öffentlichkeit dar. Aktuelle sowie abgeschlossene Projekte, die von den Bundesministerien für Bildung und Forschung (BMBF), für Umwelt, Naturschutz, Bau- und Reaktorsicherheit (BMUB), für Wirtschaft und Technologie (BMWi), für Ernährung und Landwirtschaft (BMEL) und für Verkehr, Bau und Stadtentwicklung (BMVI) gefördert werden, sind einsehbar.

\section{ABGRENZUNG DER BERECHNUNGSGRÖSSEN:}

Das BMBF fördert seit 1997 gezielt interdisziplinäre Vorhaben zu ethischen, rechtlichen und sozialen Aspekten (ELSA) der modernen Lebenswissenschaften und der Biotechnologie. Die Projekte wurden im Förderkatalog mittels der Funktion „Projektsuche” für die entsprechende Leistungsplansystematik "AA0280" (Forschung zu Rahmenbedingungen/ ELSA) recherchiert. Vorhaben zum Thema synthetische Biologie wurden anschließend händisch aus den Suchergebnissen gefiltert. Aufgrund der vorgegebenen Suchparameter ist es allerdings möglich, dass Projekte, die sich mit der synthetischen Biologie beschäftigen, aber dies nicht explizit betiteln, hier unerwähnt bleiben.

\section{GLIEDERUNG DER DARSTELLUNG:}

BMBF-geförderte ethische Begleitforschung (ELSA) zum Thema synthetische Biologie

\section{BERECHNUNGSHÄUFIGKEIT:}

jährlich

\section{AUSSAGEFÄHIGKEIT:}

Der Indikator erlaubt Rückschlüsse auf den Stellenwert eines sozial verantwortungsvollen Umgangs mit der synthetischen Biologie, wie sie von Seiten der staatlichen Ebene gefördert bzw. als notwendig betrachtet wird. Bioethische Begleitforschung bietet Raum für die Entwicklung von ethischen Leitlinien für die Forschung und deren wirtschaftliche Anwendungen, für die entsprechende Fortbildung des wissenschaftlichen Personals sowie für öffentliche Aufklärung. 
Tabelle 3: BMBF-geförderte ethische Begleitforschung (ELSA) zum Thema Synthetische Biologie

\begin{tabular}{|c|c|c|}
\hline \multirow[t]{3}{*}{ Förderkennzeichen } & \multirow[t]{3}{*}{ Thema } & Laufzeit \\
\hline & & Fördersumme \\
\hline & & Ausführende Stelle \\
\hline \multirow[t]{3}{*}{ 01GP1088 } & \multirow{3}{*}{$\begin{array}{l}\text { Klausurwochen ELSA: Ethische, rechtliche und } \\
\text { soziale Herausforderungen der Synthetischen } \\
\text { Biologie }\end{array}$} & $01.05 .2010-30.04 .2011$ \\
\hline & & $32.885 €$ \\
\hline & & Philipps-Universität Marburg \\
\hline \multirow[t]{12}{*}{$01 \mathrm{GP1003}$} & \multirow{3}{*}{$\begin{array}{l}\text { Forschungskooperation ELSA: Synthetische } \\
\text { Biologie } \\
\text { A: Eine interdisziplinäre Untersuchung zu den } \\
\text { ethischen Implikationen der synthetischen } \\
\text { Biologie } \\
\text { (Teilprojekte } 1 \text { und 5) }\end{array}$} & $01.10 .2010-30.09 .2013$ \\
\hline & & $289.269 €$ \\
\hline & & Albert-Ludwigs-Universität Freiburg \\
\hline & \multirow{3}{*}{$\begin{array}{l}\text { B: Leben schaffen - Gott spielen? Eine theolo- } \\
\text { gische Analyse der Synthetischen Biologie } \\
\text { (Teilprojekt 2) }\end{array}$} & $01.10 .2010-31.12 .2013$ \\
\hline & & $108.071 €$ \\
\hline & & $\begin{array}{l}\text { Friedrich-Alexander-Universität Erlangen- } \\
\text { Nürnberg }\end{array}$ \\
\hline & \multirow{3}{*}{$\begin{array}{l}\text { C: Chancen und Risiken } \\
\text { (Teilprojekt 3) }\end{array}$} & $01.10 .2010-30.09 .2013$ \\
\hline & & $112.411 €$ \\
\hline & & Karlsruher Institut für Technologie \\
\hline & \multirow{3}{*}{$\begin{array}{l}\text { D: Eine Analyse der rechtlichen Rahmenbe- } \\
\text { dingungen } \\
\text { (Teilprojekt 4) }\end{array}$} & $01.10 .2010-31.12 .2013$ \\
\hline & & $119.770 €$ \\
\hline & & Medizinische Hochschule Hannover \\
\hline \multirow[t]{3}{*}{ 01GP1381 } & \multirow{3}{*}{$\begin{array}{l}\text { Klausurwochen ELSA: Beurteilung des } \\
\text { gesellschaftlichen Diskurses zur Synthetischen } \\
\text { Biologie }\end{array}$} & $01.12 .2013-31.05 .2015$ \\
\hline & & $63.113 €$ \\
\hline & & $\begin{array}{l}\text { Europäische Akademie zur Erforschung von } \\
\text { Folgen wissenschaftlich-technischer Entwick- } \\
\text { lungen Bad Neuenahr-Ahrweiler GmbH }\end{array}$ \\
\hline
\end{tabular}

Quelle: siehe Indikatorenblatt SB-06. 
Laufende Nr:: SB-07

Problemfeld: Öffentliche Wahrnehmung und Bewertung + Dialogverpflichtung der Forschung

\section{INDIKATOR: ÖFFENTLICHE VERANSTALTUNGEN ZUR SYNTHETISCHEN BIOLOGIE IN DEUTSCHLAND}

\section{DATENQUELLE:}

Informationsdienst Wissenschaft e. V. Unter:

www.idw-online.de

Zugriff: April 2014, Stand: Dezember 2013.

\section{VERFÜGBARKEIT DER DATEN:}

\section{öffentlich}

Der Informationsdienst Wissenschaft e. V. (idw) betreibt ein öffentlich zugängliches Internetportal für Pressemitteilungen und Veranstaltungsankündigungen von mehreren Hundert angeschlossenen wissenschaftlichen Einrichtungen, Vereinen und Unternehmen. Laut Auskunft des idw werden die Termineinträge in den Wissenschaftskalender seit 1999 geführt.

\section{ABGRENZUNG DER BERECHNUNGSGRÖSSEN:}

Für die Recherche wurden im idw-Archiv Veranstaltungen zum Suchbegriff "synthetische Biologie" recherchiert. Die Trefferliste wurde anschließend für thematisch einschlägige Veranstaltungen händisch gefiltert, die sich gezielt an die Öffentlichkeit oder die Presse richteten. Geschlossene Fachtagungen wurden nicht aufgenommen. Mehrfache Ankündigungen einer Veranstaltung wurden zusammengefasst. Die Daten werden hier ab 2009 - dem ersten Jahr mit einschlägigen Veranstaltungen - dargestellt. Auf eine Auflistung der einzelnen Veranstaltungen wird aufgrund der zunehmenden Datenmenge im Gegensatz zu früheren Veröffentlichungen verzichtet.

\section{GLIEDERUNG DER DARSTELLUNG:}

Anzahl an öffentlichen Veranstaltungen zum Thema synthetische Biologie

\section{BERECHNUNGSHÄUFIGKEIT:}

jährlich

\section{AUSSAGEFÄHIGKEIT:}

Öffentliche Veranstaltungen können als Indiz für die Kommunikationsbereitschaft der Forschungsgemeinschaft gesehen werden. Fachergebnisse der Öffentlichkeit allgemein verständlich vorzustellen und mit ihr über die gesellschaftlichen Chancen und Risiken einer Gentechnologie zu diskutieren, stellt ein wichtiges Mittel der Wissenschaftskommunikation und Akzeptanzbildung innerhalb der Bevölkerung dar. Neben der Wissenschaft werden weitere Interessengruppen aus Politik, Wirtschaft und Zivilgesellschaft sichtbar, die in einem Bereich der Gentechnologien den Dialog mit der Öffentlichkeit suchen. 
Abbildung 11: Anzahl an öffentlichen Veranstaltungen zum Thema synthetische Biologie

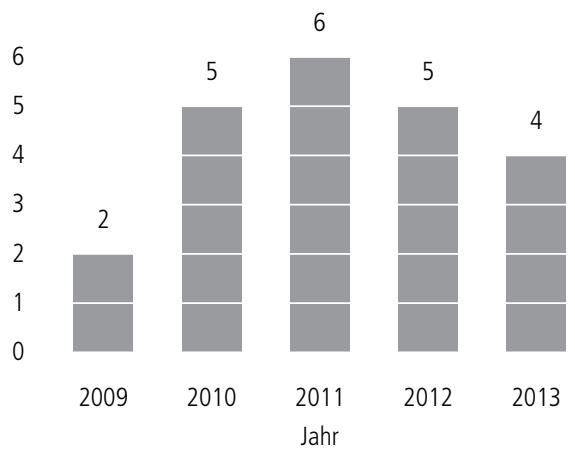

Quelle: siehe Indikatorenblatt SB-07. 
Laufende Nr:: SB-08

Problemfeld: Rechtsrahmen + Biosafety/Biosecurity

\section{INDIKATOR: DEUTSCHE STELLUNGNAHMEN ZUR REGELUNGSNOTWENDIGKEIT DER SYNTHETISCHEN BIOLOGIE}

\section{DATENQUELLE:}

Deutscher Ethikrat. Unter:

www.ethikrat.org/dateien/pdf/Perspektivenpapier_Synthetische_Biologie_2009-04-23.pdf

Zugriff: April 2014, Stand: April 2009.

Deutscher Bundestag. Wissenschaftliche Dienste. Unter:

www.bundestag.de/dokumente/analysen/2009/synthetische_biologie.pdf

Zugriff: April 2014, Stand: Juli 2009.

DFG, acatech und Leopoldina. Unter:

www.dfg.de/download/pdf/dfg_im_profil/reden_stellungnahmen/2009/stellungnahme_synthetische_biologie.pdf Zugriff: April 2014, Stand: November 2009.

Testbiotech e. V. Unter:

www.testbiotech.de/sites/default/files/Synthetische\%20Biologie_\%20Gentechnikgesetz_Testbiotech_ed.pdf

Zugriff: April 2014, Stand: September 2010

Deutsche Bundesregierung. Unter:

http://dipbt.bundestag.de/dip21/btd/17/051/1705165.pdf

Zugriff: April 2014, Stand: März 2011.

DECHEMA Arbeitskreis Systembiologie und Synthetische Biologie. Unter:

http://biotech.dechema.de/biotech_media/Downloads/Synth_Bio_2011_NEU_3.pdf

Zugriff: April 2014, Stand: Juli 2011.

Deutsche Industrievereinigung Biotechnologie (DIB) Unter:

https://www.vci.de/Downloads/PDF/Diskussionspapier-Synthetische-Biologie.pdf

Zugriff: April 2014, Stand: September 2012

Bundesamt für Verbraucherschutz und Lebensmittelsicherheit (BVL). Unter:

http://www.bvl.bund.de/SharedDocs/Downloads/06_Gentechnik/ZKBS/01_Allgemeine_Stellungnahmen_ deutsch/01_allgemeine_Themen/Synthetische_Biologie.pdf?__blob=publicationFile\&v=3

Zugriff: April 2014, Stand: November 2012.

\section{VERFÜGBARKEIT DER DATEN:}

\section{öffentlich}

Für die Recherche wurde eine Auswahl an Stellungnahmen unterschiedlicher öffentlicher Institutionen und einschlägiger Interessenverbände in Deutschland herangezogen. Die Stellungnahmen sind online auf den angegebenen Webseiten kostenlos einsehbar.

\section{ABGRENZUNG DER BERECHNUNGSGRÖSSEN:}

Die Angaben beziehen sich auf die von den unterschiedlichen Institutionen getroffenen Aussagen zu den rechtlichen Aspekten zur synthetischen Biologie.

\section{GLIEDERUNG DER DARSTELLUNG:}

Einschätzung des gegenwärtigen rechtlichen Handlungsbedarfs für die synthetische Biologie

\section{BERECHNUNGSHÄUFIGKEIT:}

fortlaufend 


\section{AUSSAGEFÄHIGKEIT:}

Der Indikator dokumentiert die Einschätzung unterschiedlicher Institutionen und Organe in Bezug auf den rechtlichen Regelungsbedarf der synthetischen Biologie in Deutschland. Sie ermöglichen eine Perspektive darauf, mit welcher Dringlichkeit eine juristische Konkretisierung gehandelt wird.

Tabelle 4: Einschätzung des gegenwärtigen rechtlichen Handlungsbedarfs für die synthetische Biologie

\begin{tabular}{|c|c|}
\hline Stellungnahme & Aussagen zu rechtlichen Aspekten \\
\hline $\begin{array}{l}\text { Deutscher Ethikrat } \\
\text { „Perspektivenpapier Synthetische } \\
\text { Biologie” } \\
\text { (April 2009) }\end{array}$ & $\begin{array}{l}\text { „Um das Missbrauchsrisiko gering zu halten, werden sowohl nationale } \\
\text { und internationale Gesetze erwogen als auch Selbstverpflichtungen der } \\
\text { Industrie, die beispielsweise ein „Wasserzeichen“ in künstlich hergestellten } \\
\text { Sequenzen, die sorgfältigen Prüfung aller Aufträge durch Synthesefirmen } \\
\text { und die Registrierung aller für die Synthese geeigneter Maschinen erwägt.” }\end{array}$ \\
\hline $\begin{array}{l}\text { Deutscher Bundestag. Wissenschaftliche } \\
\text { Dienste } \\
\text { „Aktueller Begriff Synthetische Biologie" } \\
\text { (Juli 2009) }\end{array}$ & $\begin{array}{l}\text { "Bei den Designerorganismen der Synthetischen Biologie handelt es sich } \\
\text { um gentechnisch veränderte Organismen, auf die die Regelungen des } \\
\text { deutschen Gentechnikrechts anwendbar sind. Es ergeben sich auch ver- } \\
\text { gleichbare Fragen nach der biologischen Sicherheit (biosafety) wie bei der } \\
\text { Gentechnik, z. B. bei einer unbeabsichtigten Freisetzung. Es ist aber nicht } \\
\text { auszuschließen, dass Vorschriften und Begriffsbestimmungen angepasst } \\
\text { werden müssen.” }\end{array}$ \\
\hline $\begin{array}{l}\text { DFG, acatech und Leopoldina } \\
\text { Gemeinsame Stellungnahme } \\
\text { Synthetische Biologie } \\
\text { (November 2009) }\end{array}$ & $\begin{array}{l}\text { „Es ist noch eine offene Frage, ob die Risiken der Synthetischen Biologie } \\
\text { anders gelagert oder in ihrer Größenordnung anders einzuschätzen sind als } \\
\text { die Risiken der bisherigen Genforschung. Zunächst ist davon auszugehen, } \\
\text { dass die bestehenden Regelungen und Regulierungen ausreichen, um diese } \\
\text { Risiken zu vermeiden oder abzumildern. Wichtig ist aber eine gesellschaft- } \\
\text { liche Begleitforschung, die frühzeitig neue Risiken erkennen hilft, damit } \\
\text { mögliche Fehlentwicklungen von vornherein vermieden werden können. } \\
\text { In Bezug auf die biologische Sicherheit sind die Risiken der gegenwär- } \\
\text { tigen Forschung innerhalb der Synthetischen Biologie durch gesetzliche } \\
\text { Regelungen angemessen erfasst und reguliert.” Unter Berücksichtigung } \\
\text { der Dynamik und Heterogenität der Forschungsdisziplin wird zusätzlich ein } \\
\text { unabhängiges Monitoring durch die Zentrale Kommission für die Biologi- } \\
\text { sche Sicherheit (ZKBS) sowie die Festsetzung eines Kriterienkatalogs für } \\
\text { den Umgang und die Freisetzung von neuartigen synthetischen Organismen } \\
\text { empfohlen.” }\end{array}$ \\
\hline $\begin{array}{l}\text { Testbiotech e. V. } \\
\text { "Vorschläge für die Regulierung und } \\
\text { Kontrolle der Synthetischen Biologie im } \\
\text { Rahmen des Gentechnologiegesetzes" } \\
\text { (Juni 2010) }\end{array}$ & $\begin{array}{l}\text { „Der gesetzliche Rahmen des Gentechnikgesetzes ist angesichts der Ent- } \\
\text { wicklungen im Bereich der Synthetischen Biologie und im Hinblick auf die } \\
\text { Risiken, die sich aus der Schaffung künstlicher Lebensformen ergeben, nicht } \\
\text { mehr ausreichend. Zudem weist das Gentechnikgesetz Lücken bezüglich } \\
\text { der möglichen unkontrollierten Verbreitung gentechnisch veränderter } \\
\text { Organismen auf. " }\end{array}$ \\
\hline
\end{tabular}




\section{Stellungnahme}

Deutsche Bundesregierung

"Stand und Perspektiven der

Synthetischen Biologie"

(März 2011)

\section{Aussagen zu rechtlichen Aspekten}

„Die Bundesregierung sieht derzeit in Übereinstimmung mit den Empfehlungen führender Wissenschaftsorganisationen [...] keinen gesetzlichen oder regulatorischen Handlungsbedarf, da die Sicherheitsrisiken der Synthetischen Biologie denen der bekannten biotechnologischen Methoden ähneln und durch bestehende gesetzliche Regelungen, wie insbesondere das Gentechnikgesetz, das Außenwirtschaftsgesetz und das Kriegswaffenkontrollgesetz angemessen erfasst sind. Diese gesetzlichen Regularien werden durch freiwillige Selbstverpflichtungen der Industrie unterstützt, um zu gewährleisten, dass nur vertrauenswürdige Empfänger Zugang zu potenziell zu missbrauchenden Nukleinsäuren bekommen [...]. Die Bundesregierung teilt weiterhin die in der Stellungnahme Synthetische Biologie von acatech, Leopoldina und DFG dargelegte Einschätzung, dass ein kontinuierliches wissenschaftliches Monitoring bezüglich der Chancen und Risiken der Synthetischen Biologie benötigt wird, um die schnellen Entwicklungen in diesem Forschungsfeld verantwortungsbewusst zu begleiten. Die Bundesregierung wird dahingehend von der Zentralen Kommission für die biologische Sicherheit (ZKBS), die die Bundesregierung und die Länder seit 1978 in Fragen zur Sicherheit der Gentechnik berät, unterstützt."

„Das Sicherheitsrisiko der Synthetischen Biologie ist durch das Gentechnik-Gesetz abgedeckt, sollte aber durch erweiterte Kontrollmaßnahmen noch weiter verringert werden. [...] Eine begleitende Ethik- und Technologiefolge-Diskussion ist wie bei jeder neuen Technologie erforderlich. Sie sollte begleitend zur wissenschaftlichen Entwicklung aufgrund konkreter Anwendungsszenarien erfolgen, ohne die Entwicklung neuer Methoden im Ansatz zu verhindern." „Die gegenwärtigen Arbeitsfelder der Synthetischen Biologie sind heute über eine Vielzahl von Gesetzen und Verordnungen, insbesondere das Gentechnik-, Chemikalien-, Arbeitsschutz- und Arzneimittelgesetz sowie die Biostoffverordnungabgedeckt. [...] Auch eine Reihe von Verordnungen, die den Missbrauch von Technologien verhindern sollen und die sich u.a. auch auf Produkte der Synthetischen Biologie beziehen, existieren bereits auf nationaler und internationaler Ebene. [...] Zusätzlich dazu unterstützen Wissenschaftler in der Forschung und Industrie freiwillige Selbstverpflichtungen [...]. Bezüglich der biologischen Sicherheit (Biosafety) und des Missbrauchsrisikos (Biosecurity) sind die bestehenden Gesetze nach dem heutigen Forschungsstand somit ausreichend" [...] Verantwortungsbewusstes Handeln gebietet es, die Fortentwicklung dieser neuen Technologie weiter hin aufmerksam zu beobachten, um einen möglichen Regulierungsbedarf zu erkennen und ggf. aufzugreifen. "

Bundesamt für Verbraucherschutz und Lebensmittelsicherheit

Zentrale Kommission für die Biologische Sicherheit (ZKBS)

"Monitoring der Synthetischen Biologie in Deutschland"

(November 2012)
"Zusammenfassend lässt sich also sagen, dass die derzeit in Deutschland in der Synthetischen Biologie verfolgten Forschungsansätze kein Biosicherheits-spezifisches Gefährdungspotential bergen, das über das von "klassischen" gentechnischen Versuchen hinausgeht und dem nicht durch die konsequente Anwendung des GenTG begegnet werden kann. Beim aktuellen Stand der Forschung werden alle Forschungsansätze mit Ausnahme der Synthese von Nukleinsäuren vom GenTG erfasst. Ein Abgleich des internationalen Forschungsstandes der verschiedenen Forschungsfelder der Synthetischen Biologie und ihrer Bedeutung für die biologische Sicherheit wird derze durchgefährt."408, an 26.04.2023, 10:21:38 
Laufende Nr:: SB-09

Problemfeld: Öffentliche Wahrnehmung

\section{INDIKATOR: INTERNETPRÄSENZ ZUM STICHWORT SYNTHETISCHE BIOLOGIE}

\section{DATENQUELLE:}

Google - Suchmaschine. Unter:

www.google.de

Zugriff: Oktober 2014, Stand: k. A.

\section{VERFÜGBARKEIT DER DATEN:}

\section{öffentlich}

Die Recherche mit der Internet-Suchmaschine ist kostenlos und wurde jeweils über deren deutsches Portal mit den Standardeinstellungen unter Nutzung des Webbrowsers Mozilla Firefox (jeweils aktuellste Version) durchgeführt.

\section{ABGRENZUNG DER BERECHNUNGSGRÖSSEN:}

Für die Recherche wurde das Stichwort "synthetische Biologie" mit der Suchmaschine gesucht und die Anzahl an gefundenen Webseiten gemittelt. Es erfolgte keine weiterführende qualitative Auswertung der Suchergebnisse. Die Datenerhebung erfolgt seit April 2011. Es muss darauf hingewiesen werden, dass der Internetauftritt der Suchmaschine ständig weiterentwickelt wird und dadurch bedingte Abweichungen zwischen den einzelnen Monaten möglich sind.

\section{GLIEDERUNG DER DARSTELLUNG:}

Trefferanzahl bei der Stichwortsuche in Google

\section{BERECHNUNGSHÄUFIGKEIT:}

monatlich

\section{AUSSAGEFÄHIGKEIT:}

Der Indikator dokumentiert die öffentliche Auseinandersetzung mit der synthetischen Biologie anhand von verfügbaren Webseiten im Internet. Die ausgewählte Suchmaschine stellt das am häufigsten in Deutschland genutzte Portal für die Online-Recherche dar. Die interessierte Öffentlichkeit kann sich auf diesem Weg weiterführend über das Forschungsfeld informieren. Es ist allerdings möglich, dass die von der Suchmaschine vorgeschlagenen Webseiten sich nicht ausschließlich mit relevanter Forschung befassen, sondern dass die synthetische Biologie nur als randständiges Thema auftritt. Außerdem ist die Qualität der online präsentierten Informationen in Bezug auf Seriosität, Vollständigkeit und Aktualität individuell verschieden und für Fachfremde nicht unmittelbar einschätzbar. 
Abbildung 12: Trefferanzahl bei der Stichwortsuche in Google

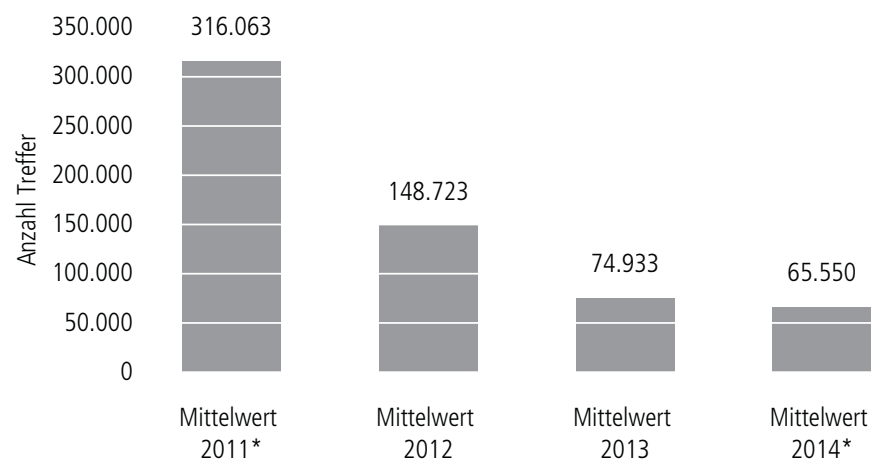

* Daten ab April 2011 bzw. bis Oktober 2014

Quelle: siehe Indikatorenblatt SB-09. 
Laufende Nr:: SB-10

Problemfeld: Forschungsstandort Deutschland + Realisierung wissenschaftlicher Zielsetzungen

\section{INDIKATOR: FÖRDERMASSNAHMEN DER DFG FÜR DIE SYNTHETISCHE BIOLOGIE}

\section{DATENQUELLE:}

GEPRIS - Geförderte Projekte Informationssystem. Unter:

http://gepris.dfg.de

Zugriff: April 2014 Stand: April 2014

\section{VERFÜGBARKEIT DER DATEN:}

\section{öffentlich}

GEPRIS ist eine Internetplattform, die über die Fördermaßnahmen der Deutschen Forschungsgemeinschaft (DFG) informiert. Laut DFG sind hier Daten zu bewilligten Projekten aus allen DFG-Förderprogrammen seit dem 01.01.1999 aufgeführt. Die Datenbank wird fortlaufend aktualisiert. Der Zugang ist kostlos. Es werden keine Fördersummen für einzelne Projekte in GEPRIS ausgewiesen.

\section{ABGRENZUNG DER BERECHNUNGSGRÖSSEN:}

Für die Recherche relevanter DFG-geförderter Projekte wurde als Stichworte "synthetische* Biologie" und "synthetic biology" verwendet, um sowohl deutsche als auch englische Informationen zu erfassen ("Suche" in "Projekte" exkl. geförderter Teilprojekte und inkl. Projekte ohne Abschlussbericht). Es wurde keine weiterführende qualitative Filterung der Suchergebnisse vorgenommen. Die Detailinformationen der einzelnen Projekte wurden den verlinkten Projektbeschreibungen auf GEPRIS entnommen. Es wurden alle abgeschlossenen und laufenden Projekte für die Jahre 1999-2013 recherchiert.

\section{GLIEDERUNG DER DARSTELLUNG:}

Anzahl an DFG-geförderten Projekten zum Themenbereich der synthetischen Biologie

\section{BERECHNUNGSHÄUFIGKEIT:}

jährlich

\section{AUSSAGEFÄHIGKEIT:}

Die Deutsche Forschungsgemeinschaft (DFG) versteht sich als Selbstverwaltungsorgan der deutschen Forschung. Sie stellt eine wichtige Fördereinrichtung für die Wissenschaft in Deutschland dar - vor allem in Hinblick auf den stetig zunehmenden Stellenwert der Einwerbung von Drittmitteln an Hochschulen und außeruniversitären Forschungsinstituten. Das Ausmaß der DFG-Förderung für die synthetische Biologie erlaubt Rückschlüsse auf das wissenschaftliche und wirtschaftliche Potenzial des Feldes. Für eine umfassende Beurteilung ist eine langfristige Beobachtung angezeigt. Zudem sind in diesem Zusammenhang weitere Quellen der Finanzierung zu berücksichtigen. 
Abbildung 13: Anzahl an DFG-geförderten Projekten zum Themenbereich der synthetischen Biologie

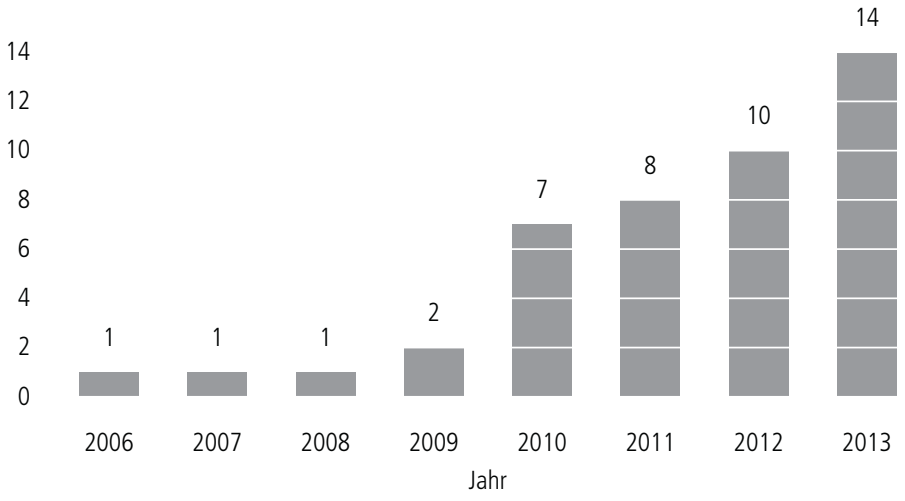

Es wurden keine Projekte vor 2006 in GEPRIS zum gewählten Suchbegriff genannt. Quelle: siehe Indikatorenblatt SB-10. 
Laufende Nr:: SB-11

Problemfeld: Öffentliche Wahrnehmung

\section{INDIKATOR: ÖFFENTLICHE WAHRNEHMUNG DER SYNTHETISCHEN BIOLOGIE IM EU-RAUM}

\section{DATENQUELLE:}

Eurobarometer-Spezialumfrage Nr. 341 (Umfragewelle EB73.1): Europeans and Biotechnologie in 2010. Winds of change? Unter:

http://ec.europa.eu/public_opinion/archives/ebs/ebs_341_winds_en.pdf Zugriff: April 2014, Stand: Oktober 2010.

Hampel, J. (2012): Synthetische Biologie - eine unbekannte Technologie. In: Köchy, K./Hümpel, A. (Hrsg.): Synthetische Biologie. Entwicklung einer neuen Ingenieurbiologie? Dornburg:237-255. Unter:

http://edoc.bbaw.de/volltexte/2014/2570/pdf/2012_Themenband_Synthetische_Biologie_PDF_EDOC_2013.pdf Zugriff: April 2014, Stand: Dezember 2012.

\section{VERFÜGBARKEIT DER DATEN:}

öffentlich

Die Europäische Kommission lässt seit 1973 regelmäßig sogenannte „Eurobarometer"-Umfragen zur Erforschung des öffentlichen Meinungsbildes in seinen Mitgliedstaaten durchführen (http://ec.europa.eu/public_opinion/index_en.htm [22.07.2013]). Es wird ein breiter Themenkatalog abgedeckt, der Fragen des Zusammenlebens in der Europäischen Gemeinschaft untersucht. Die beauftragten Studien und Berichte sind über das Online-Portal der Europäischen Kommission in Englisch verfügbar. Zusammenfassungen sind z. T. auch in Deutsch verfügbar. Der Zugang ist kostlos.

\section{ABGRENZUNG DER BERECHNUNGSGRÖSSEN:}

Als Grundlage für den vorliegenden Indikator dienen Daten aus der Eurobarometer-Umfragewelle EB73.1 zu Biowissenschaften und Biotechnologie ("Life Sciences and Biotechnology"), die im Februar 2010 in insgesamt 32 europäischen Ländern durchgeführt wurde (EU27 inkl. Kroatien, Island, Norwegen, Schweiz und Türkei). Es ist die siebente Umfrage zur öffentlichen Wahrnehmung dieses speziellen Themenbereichs, der die Gentechnologie („genetic engineering”) einschließt. Vorangegangene Umfragen wurden 1991 (EB35.1), 1993 (EB39.1), 1996 (EB46.1), 1999 (EB52.1), 2002 (EB58.0) und 2005 (EB63.1) durchgeführt. Die synthetische Biologie wurde erst in der letzten Umfrage 2010 als wichtiges Element der Biotechnologie aufgenommen und abgefragt. Für Eurobarometer-Umfragen werden in der Regel je Land 1000 Personen befragt mit Ausnahme sehr kleiner (Malta, Zypern und Luxemburg je 500 Befragte) und sehr großer (Vereinigtes Königreich mit 1300 Befragten, Deutschland mit 1500 Befragten) Länder. Für die 27 EU-Länder umfasste die Stichprobe in EB73.1 insgesamt 26.676 Befragte. Der vollständige Fragenkatalog und die Umfrageergebnisse sind in 0. g. Spezial-Eurobarometer 2010 veröffentlicht worden. Für den "Gentechnologiebericht" wurden die Umfrageergebnisse für einen interdisziplinären Sammelband zur synthetischen Biologie mit Blick auf die Rahmenbedingungen in Deutschland 2012 von Jürgen Hampel ergänzend ausgewertet. Aus Gründen der Transparenz werden die verfügbaren Daten im aktuellen Gentechnologiebericht veröffentlicht, da das Thema synthetische Biologie hier erstmalig im Berichtsformat aufgegriffen wurde. Eine Aktualisierung der Daten ist zur Zeit noch nicht absehbar.

\section{GLIEDERUNG DER DARSTELLUNG:}

a) Bekanntheitsgrad der synthetischen Biologie in Deutschland und Europa (in Prozent)

b) Gewünschte Informationen zur synthetischen Biologie (in Prozent) an erster, zweiter oder dritter Stelle genannt

c) Einstellungen zur synthetischen Biologie in Deutschland und Europa (in Prozent)

\section{BERECHNUNGSHÄUFIGKEIT:}

einmalig 


\section{AUSSAGEFÄHIGKEIT:}

Im Rahmen der verwendeten Eurobarometer-Befragung wurde die öffentliche Meinung zu verschiedensten Bereichen der modernen Biotechnologie erfasst: synthetische Biologie neben $u$. a. gentechnisch modifizierten Lebensmitteln und Stammzellforschung. Es wurden Bekanntheitsgrad und generelles Interesse am Thema erfragt ebenso wie die Einstellung zur möglichen Anwendung der synthetischen Biologie und ihr (angenommener) rechtlicher Regulierungsbedarf. Nationalität, Geschlecht und sozio-ökonomischer Hintergrund der Befragten flossen in die Analyse der Umfrageergebenisse ein und ergaben ein differenziertes Meinungsbild zur synthetischen Biologie in Europa, das z.B. für die Eruierung geeigneter Förder-, Öffentlichkeits- und Regulierungsmaßnahmen innerhalb Deutschlands oder der EU herangezogen werden kann. Die Umfrageergebnisse skizzieren den gesellschaftlichen Rahmen innerhalb dessen, sich die Synthetische Biologie aktuell entwickelt und zeigen mögliche Ansatzpunkte für die Gestaltung eines erfolgreichen öffentlichen Dialogs auf.

a) Abbildung 14: Bekanntheitsgrad der synthetischen Biologie in Deutschland und Europa (in Prozent)

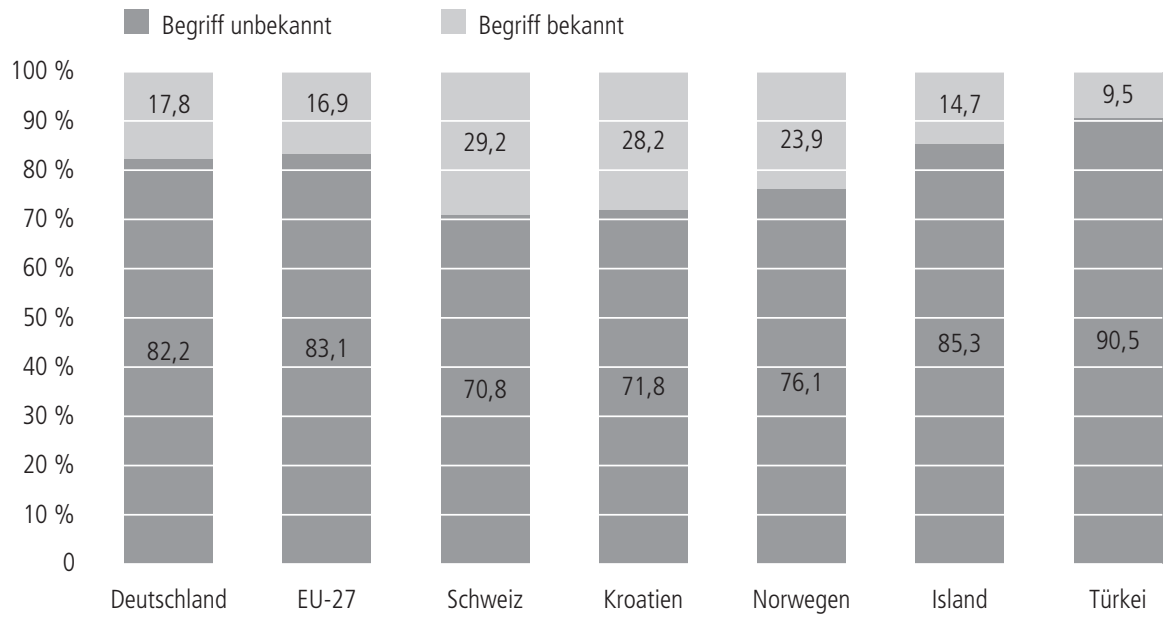

Quelle: siehe Indikatorenblatt SB-011 
b) Abbildung 15: Gewünschte Informationen zur synthetischen Biologie (in Prozent) an erster, zweiter oder dritter Stelle genannt

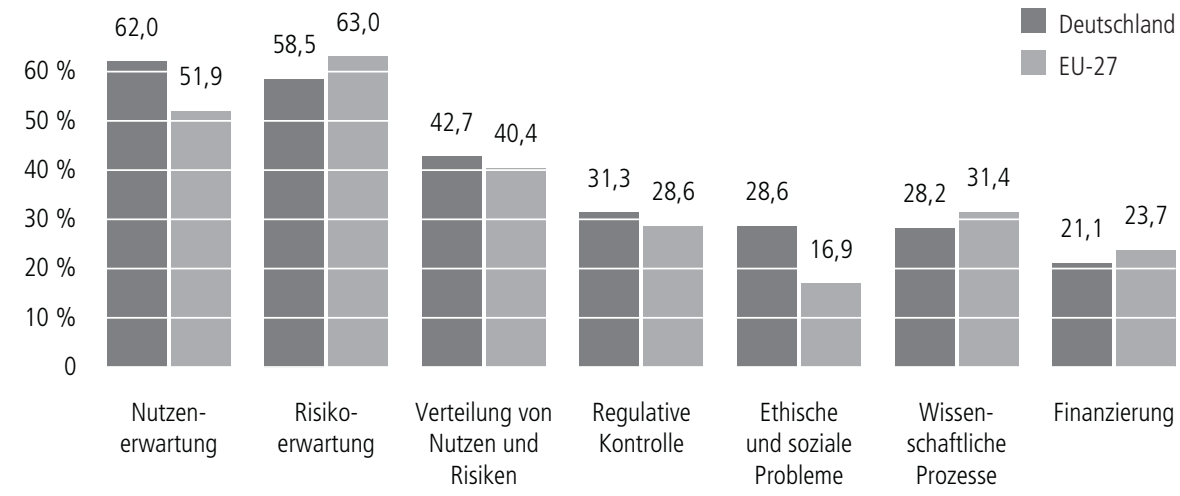

Quelle: siehe Indikatorenblatt SB-011.

c) Abbildung 16: Einstellungen zur synthetischen Biologie in Deutschland und Europa (in Prozent)

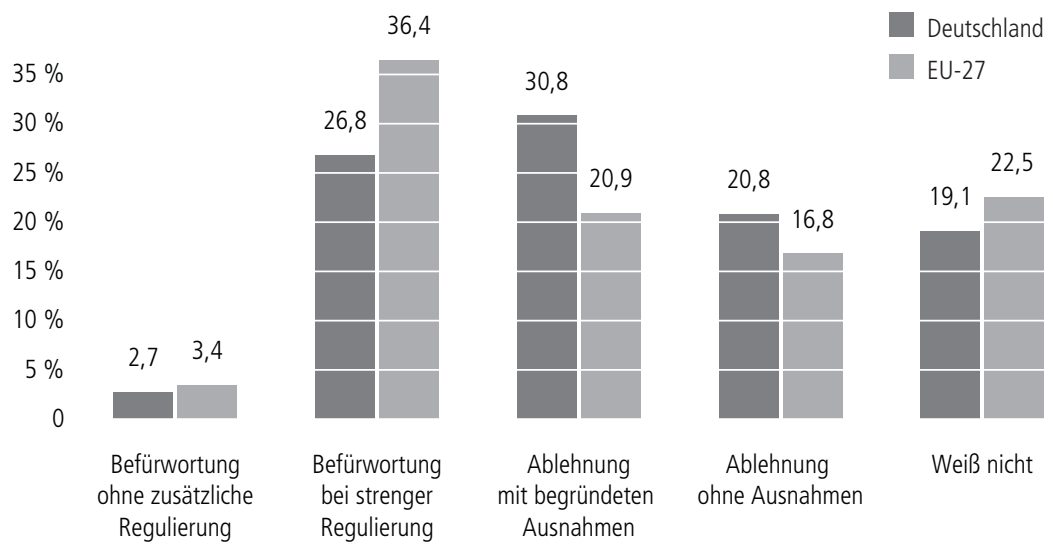




\subsubsection{Zusammenfassung}

Es ergibt sich in der Gesamtschau folgendes Bild für den Themenbereich der synthetischen Biologie:

- Für den Zeitraum von 2001 bis 2013 listete die Scopus-Datenbank zum Recherchezeitpunkt insgesamt 1720 Fachartikel zum Suchbegriff „synthetic biology“. Der Umfang an Veröffentlichungen ist verglichen mit anderen Fachbereichen (vgl. z. B. Indikator GT-03) insgesamt deutlich geringer. Erst ab der zweiten Berichtsphase sind Fachartikel in nennenswertem Umfang mit Bezug zur Synthetischen Biologie ausgewiesenen. Die Anzahl an Veröffentlichungen ist insgesamt stetig über die Jahre gestiegen. In Europa werden vor allem seit 2007 zunehmend Forschungsergebnisse mit ausgewiesenem Bezug zur Synthetischen Biologie (,synthetic biology“) veröffentlicht werden (SB-01).

- Vor 2004 werden in den Archiven der ausgewählten Medien keine Artikel zum Thema ausgewiesen. Seitdem hat der Umfang der Berichterstattung über die Synthetische Biologie allerdings zugenommen mit einem erkennbaren Höhepunkt im Jahr 2010. Die lässt sich durch die Vorstellung des ersten Bakteriums mit einem synthetisch im Labor synthetisierten Genom durch Gibson et al. (2010) erklären. Die Synthetische Biologie ist in der öffentlichen Berichterstattung seltener vertreten als andere Themen des Gentechnologieberichts (SB-02). Da die synthetische Biologie erst seit wenigen Jahren als eigene Disziplin wahrgenommen und als solche (auch von den hier aktiven Akteuren) benannt wird, erklärt sich zudem, die zwar sichtbare, dennoch im Vergleich zu anderen Themenbereichen niedrige Publikationsleistung. (SB-03).

- Es zeigt sich eine über die Jahre zunehmende Beteiligung am studentischen iGEMWettbewerb. Als neue Tendenz in den letzten beiden Jahren wurde sichtbar, dass sich der Anstieg auf die Anzahl an Teams pro Land und nicht auf die Anzahl beteiligter Länder bezieht. Hier ist vor allem auf die wachsende Beteiligung chinesischer Teams hinzuweisen. Gemessen am Gesamtwettbewerb waren 2013 die deutschen Teams überproportional im Finale vertreten (SB-04).

- Die Europäische Union förderte erstmalig 2002 ein Projekt mit ausgewiesenem Bezug zur Synthetischen Biologie. Deutschland war an diesem Projekt beteiligt. Seit 2007 werden im 7. Forschungsrahmenprogramm in zunehmenden Umfang Fördermaßnahmen von der EU bewilligt (SB-05). Die BMBF-Förderung dokumentiert das allgemeine Bewusstsein für die Notwendigkeit einer umfassenden Auseinandersetzung mit den Rahmenbedingungen (ELSA) für die synthetische Biologie in Deutschland (SB-06). 
- Die über den Informationsdienst Wissenschaft (idw) angekündigten öffentlichen Veranstaltungen dokumentieren ein öffentliches Interesse an der synthetischen Biologie und eine Wertschätzung der Dialogverpflichtung von Seiten der Forschungsgemeinschaft (SB-07). Auch die steigende Anzahl von Stellungnahmen unterschiedlichster Stoßrichtung über die letzten beiden Beobachtungszeiträume hinweg, zeugt von der Wahrnehmung der synthetischen Biologie als gesellschaftspolitisch relevantes Thema (SB-08).

- Internet-Suchmaschinen bieten dem Laien eine Erstorientierung in ein Thema. Dabei ist seit 2011 jährlich ein Rückgang an Trefferzahlen zum Stichwort „synthetische Biologie“ zu verzeichnen. 2013 gab es aber immer noch rund 75.000 Treffern (SB-09).

- Die Deutsche Forschungsgemeinschaft förderte vor dem Jahr 2006 keine Projekte mit ausgewiesenem Bezug zur Synthetischen Biologie. Die Anzahl an laufenden Projekten ist sehr gering, aber seit dem Jahr 2008 stetig steigend. Ihren bisherigen Höchstwert erreichte die DFG-Förderung im vergangenen Jahr 2013 mit insgesamt 14 laufenden Projekten, die vor allem in den Bereich der Einzelförderung fallen (SB10).

- Die Daten des Eurobarometers 73.1 zeigen, dass die synthetische Biologie der Bevölkerung im EU-Raum mehrheitlich noch kein Begriff ist und vielleicht gerade deshalb ihr Einsatz kaum uneingeschränkt befürwortet wird. Informationsbedarf besteht vor allem hinsichtlich des Nutzens und der Risiken - in Deutschland stehen dabei im Gegensatz zum EU-Durchschnitt die möglichen Gefahren der synthetischen Biologie im Vordergrund (SB-11).

\subsection{Literatur}

Acevedo-Rocha, C. G./Budisa, N. (2011): On the road towards chemically modified organisms endowed with a genetic firewall. In: Angew Chem Int Ed Engl 50(31):6960-6962.

Agapakis, C. M./Silver, P. A. (2009): Synthetic biology: exploring and exploiting genetic modularity through the design of novel biological networks. In: Mol Biosyst 5(7):704-713.

Binder, P. M./Danchin, A. (2011): Life's demons: information and order in biology. What subcellular machines gather and process the information necessary to sustain life? In: EMBO Rep 12(6):495499.

Budisa, N. (2004): Prolegomena to future experimental efforts on genetic code engineering by expanding its amino acid repertoire. In: Angew Chem Int Ed Engl 43(47):6426-6463.

Budisa, N. (2005): Engineering the Genetic Code. Weinheim.

Budisa, N. (2012): A brief history of the "Synthesis of Life". In: Nova Acta Leopoldina 394:79-97. 
Cello, J. et al. (2002): Chemical synthesis of poliovirus cDNA: generation of infectious virus in the absence of natural template. In: Science 297(5583):1016-1018.

Cowie, D. B./Cohen, G. N. (1957): Biosynthesis by Escherichia coli of active altered proteins containing selenium instead of sulfur. In: Biochim Biophys Acta 26(2):252-261.

Crick, F. H. C. (1965): Recent Research in Molecular Biology: Introduction. In: Br Med Bull 21(3):183186.

Dueber, J. E. et al. (2009): Synthetic protein scaffolds provide modular control over metabolic flux. In: Nat Biotechnol 27(8):753-759.

Fabret, C. et al. (2002): A new mutation delivery system for genome-scale approaches in Bacillus subtilis. In: Mol Microbiol 46(1):25-36.

Feher, T. et al. (2007): Systematic genome reductions: theoretical and experimental approaches. In: Chem Rev 107(8):3498-3513.

Fischer, E. (1907): Synthetical chemistry in its relation to biology (Faraday Lecture). In: J Chem Soc Chem Commun 91:1749-1765.

Fischer, E. (1915): Die Kaiser-Wilhelm-Institute und der Zusammenhang von organischer Chemie und Biologie. Berlin.

Fontecave, M. (2010): Understanding Life as Molecules: Reductionism versus Vitalism. In: Angew Chem Int Ed Engl 49(24):4016-4019.

Gamborg, O. L. (1975): Plant tissue culture methods in somatic hybridization by protoplast fusion and transformation. In: Adv Exp Med Biol 62:45-63.

Gibson, D. G. et al. (2010): Creation of a bacterial cell controlled by a chemically synthesized genome. In: Science 329(5987):52-56.

Gil, F. et al. (2004): Determination of the core of a minimal bacterial gene set. In: Microbiol Mol Biol Rev 68(3):518-537.

Gordon, R./Melvin, C. A. (2003): Reverse engineering the embryo: a graduate course in developmental biology for engineering students at the University of Manitoba, Canada. In: Int J Dev Biol 47(23):183-187.

Hein, G. E. (1961): The Liebig-Pasteur controversy: Vitality without vitalism. In: J Chem Educ 38(12):614-620.

Herdewijn, P./Marlière, P. (2009): Toward safe genetically modified organisms through the chemical diversification of nucleic acids. In: Chem Biodivers 6(6):791-808.

Hoesl M. G./Budisa, N. (2012): Recent advances in genetic code engineering in Escherichia coli. In: Curr Opin Biotechnol, Online-Publikation 09.01.2012. Unter: http://dx.doi.org/10.1016/j.copbio.2011.12.027 [16.07.2012].

Jewett, M. C./Forster, A. C. (2010): Update on designing and building minimal cells. In: Curr Opin Biotechnol 21(5): 697-703. 
Koonin, E. V. et al. (1997): Comparison of archaeal and bacterial genomes: computer analysis of protein sequences predicts novel functions and suggests a chimeric origin for the archaea. In: Mol Microbiol 25(4):619-637.

Kühner, S. et al. (2009): Proteome organization in a genome-reduced bacterium. In: Science 326(5957):1235-1240.

Lagesen, K et al. (2010): Genome update: the 1000th genome - a cautionary tale. In: Microbiology 156(Pt 3):603-608.

Luisi, P. L. (2007): Chemical aspects of synthetic biology. In: Chem Biodivers 4(4):603-621.

Luisi, P. L./Stano, P. (2011): Synthetic biology: minimal cell mimicry. In: Nat Chem 3(10):755-756.

Marlière, P. (2009): The farther, the safer: a manifesto for securely navigating synthetic species away from the old living world. In: Syst Synth Biol 3(1-4):77-84.

Marlière, P. et al. (2011): Chemical evolution of a bacterium's genome. In: Angew Chem Int Ed Engl 50(31):7109-7114.

Multhauf, R. P. (1966): The Origins of Chemistry. London.

Mushegian, A. R./Koonin, A. R. (1996): A minimal gene set for cellular life derived by comparison of complete bacterial genomes. In: Proc Natl Acad Sci USA 93(19):10268-10273.

Mushegian, A (1999): The minimal genome concept. In: Curr Opin Genet Dev 9(6):709-714.

Nirenberg, M. (2004): Historical review: Deciphering the genetic code - a personal account. In: Trends Biochem Sci 29(1):46-54.

Panke, S. (2008). Synthetic Biology - Engineering in Biotechnology. A report written on behalf of the Committee on applied Bioscience, Swiss Academy of Engineering Sciences. Online unter: www. bsse.ethz.ch/bpl/publications/SATW.pdf [16.07.2012].

Pezo, V. et al. (2004): Artificially ambiguous genetic code confers growth yield advantage. In: Proc Natl Acad Sci U S A 101(23):8593-8597.

Rasmussen, S. et al. (Hrsg.) (2008): Protocells. Bridging Nonliving and Living Matter. Cambridge/London.

Schmidt, M. (2010): Xenobiology: A new form of life as the ultimate biosafety tool. In: Bioessays 32(4)322-331.

Schultz, D. W./Yarus, M. (1996): On malleability in the genetic code. In: J Mol Evol 42(5):597-601.

Schummer, J. (2011): Das Gotteshandwerk: Die künstliche Herstellung von Leben im Labor. Berlin.

Siegel, J. B. et al. (2010): Computational design of an enzyme catalyst for a stereoselective bimolecular Diels-Alder reaction. In: Science 329(5989):309-313.

Spiegelman, S et al. (1970): Characterization of the Products of RNA-directed DNA Polymerases in Oncogenic RNA Viruses. In: Nature 227(5258):563-567.

Stanek, M. T. et al. (2009): Identification and dynamics of a beneficial mutation in a long-term evolution experiment with Escherichia coli. In: BMC Evol Biol 9:302. 
Szathmary, E. et al. (2005): Evolutionary Potential and Requirements for Minimal Protocells. In: Walde, P. (Hrsg.): Prebiotic Chemistry: From Simple Amphiphiles to Protocell Models (Topics in Current Chemistry). Berlin/Heidelberg:167-211.

Walde, P. (2010): Building artificial cells and protocell models: experimental approaches with lipid vesicles. In: Bioessays 32(4):296-303.

Wang, H. et al. (2007): Evolved orthogonal ribosomes enhance the efficiency of synthetic genetic code expansion. In: Nat Biotechnol 25(7):770-777.

Yeh, B. J./Lim, W. A. (2007): Synthetic biology: lessons from the history of synthetic organic chemistry. In: Nat Chem Biol. 3(9):521-525.

Yus, E. et al. (2009): Impact of genome reduction on bacterial metabolism and its regulation. In: Science 326(5957):1263-1268. 
